This is the final peer-reviewed accepted manuscript of:

Pondrelli M; Rossi AP; Le Deit L; Fueten F; van Gasselt S; Glamoclija M; CAVALAZZI, BARBARA; Hauber E;

Franchi F; Pozzobon R.: Equatorial Layered Deposits in Arabia Terra, Mars: Facies and process variability.

GEOLOGICAL SOCIETY OF AMERICA BULLETIN_127. 0016-7606. DOI: 10.1130/B31225.1

The final published version is available online at: $\mathrm{http} / / / \mathrm{dx} . \mathrm{doi} .0 \mathrm{org} / 10.1130 / \mathrm{B} 31225.1$

Rights / License:

The terms and conditions for the reuse of this version of the manuscript are specified in the publishing policy. For all terms of use and more information see the publisher's website.

This item was downloaded from IRIS Università di Bologna (https://cris.unibo.it/)

When citing, please refer to the published version. 


\title{
Equatorial layered deposits in Arabia Terra, Mars: Facies and process variability
}

\author{
Monica Pondrelli ${ }^{1, \dagger}$, Angelo Pio Rossi ${ }^{2}$, Laetitia Le Deit ${ }^{3}$, Frank Fueten ${ }^{4}$, Stephan van Gasselt ${ }^{5}$, \\ Mihaela Glamoclija ${ }^{6}$, Barbara Cavalazzi ${ }^{7}$, Ernst Hauber ${ }^{8}$, Fulvio Franchi ${ }^{9}$, and Riccardo Pozzobon ${ }^{10,11}$ \\ ${ }^{1}$ International Research School of Planetary Sciences, Università d'Annunzio, viale Pindaro 42, 65127 Pescara, Italy \\ ${ }_{2}^{2}$ Jacobs University Bremen, Campus Ring 1, 28759 Bremen, Germany \\ ${ }^{3}$ Laboratoire de Planétologie et Géodynamique, LPG-Nantes, CNRS UMR 6112, Université de Nantes, 2 rue de la Houssinière, \\ 44322 Nantes, France \\ ${ }^{4}$ Department of Earth Science, Brock University, 500 Glenridge Avenue, St. Catharines, Ontario L2S 3A1, Canada \\ ${ }^{5}$ Institut für Geologische Wissenschaften, Freie Universität, Malteserstrasse 74-100, D-232 D-12249 Berlin, Germany \\ ${ }^{6}$ Department of Earth and Environmental Sciences, Rutgers University, 101 Warren Street, Newark, New Jersey 07102, USA \\ ${ }^{7}$ Dipartimento di Scienze Biologiche, Geologiche e Ambientali, Università di Bologna, via Zamboni 67, 40127 Bologna, Italy \\ ${ }^{8}$ Institut für Planetenforschung, German Aerospace Center (DLR), Rutherfordstrasse 2, D-12489 Berlin-Adlershof, Germany \\ ${ }^{9}$ ISMAR-CNR, U.O.S.-Bologna, via Gobetti 101, 40129 Bologna, Italy \\ ${ }^{10}$ DISPUTer, Università d'Annunzio, via dei Vestini 31, 66013 Chieti, Italy \\ ${ }^{11}$ Dipartimento di Geoscienze, Università degli Studi di Padova, Via G. Gradenigo 6, 35131 Padova, Italy
}

\section{ABSTRACT}

We investigated the equatorial layered deposits (ELDs) of Arabia Terra, Mars, in Firsoff crater and on the adjacent plateau. We produced a detailed geological map that included a survey of the relative stratigraphic relations and crater count dating. We reconstructed the geometry of the layered deposits and inferred some compositional constraints. ELDs drape and onlap the plateau materials of late Noachian age, while they are unconformably covered by early and middle Amazonian units. ELDs show the presence of polyhydrated sulfates. The bulge morphology of the Firsoff crater ELDs appears to be largely depositional. The ELDs on the plateau display a sheet-drape geometry. ELDs show different characteristics between the crater and the plateau occurrences. In the crater they consist of mounds made of breccia sometimes displaying an apical pit laterally grading into a light-toned layered unit disrupted in a meter-scale polygonal pattern. These units are commonly associated with fissure ridges suggestive of subsurface sources. We interpret the ELDs inside the craters as spring deposits, originated by fluid upwelling through the pathways likely provided by the fractures related to the crater formations, and debouching at the surface

${ }^{\dagger}$ E-mail: monica@irsps.unich.it through the fissure ridges and the mounds, leading to evaporite precipitation. On the plateau, ELDs consist of rare mounds, flatlying deposits, and cross-bedded dune fields. We interpret these mounds as possible smaller spring deposits, the flat-lying deposits as playa deposits, and the cross-bedded dune fields as aeolian deposits. Groundwater fluctuations appear to be the major factor controlling ELD deposition.

\section{INTRODUCTION}

Layered deposits are very common on Mars at all scales (Thomas et al., 1992; Chapman and Tanaka, 2001; Malin and Edgett, 2000; Williams et al., 2003; Beyer et al., 2012). Among them, light-toned layered deposits are widespread in various locations in the equatorial regions of Mars, including the Valles Marineris and the chaotic terrains (Lucchitta et al., 1992; Chapman and Tanaka, 2002), crater bulges (such as Gale and Becquerel craters) (Lewis et al., 2008; Kite et al., 2013a, 2013b; Le Deit et al., 2013), and Meridiani Planum (Grotzinger et al., 2005; McLennan et al., 2005), and are grouped under the informal name of equatorial layered deposits (ELDs) (Hynek et al., 2002; Okubo et al., 2009; "Hesperian and Noachian highland undivided unit" of Tanaka et al., 2014). However, those lighttoned layered deposits that can be confidently interpreted as being deposited by fluvio-deltaic systems are excluded from this definition (e.g., Pondrelli et al., 2011b).

The genesis of the ELDs has been attributed to many different depositional processes and environments, including lacustrine (Lucchitta et al., 1992; Newsom et al., 2003), sub-ice volcanism (Chapman and Tanaka, 2001; Komatsu et al., 2004), weathering of basalts (Madden et al., 2004), pyroclastic (Scott and Tanaka, 1982; Hynek et al., 2003; Kerber et al., 2012), impact base surge (Knauth et al., 2005), and dust airfall (Tanaka, 2000; Michalski and Niles, 2012). Interplay between airfall and aeolian processes and groundwater fluctuations, leading to episodes of evaporite precipitation, has been proposed by Grotzinger et al. (2005), AndrewsHanna et al. (2007, 2010), Murchie et al. (2009), Andrews-Hanna and Lewis (2011), and Zabrusky et al. (2012). Ori and Baliva (1999) discussed the possibility of an interaction between lacustrine deposition and hydrothermal vents or large mud volcanoes. Groundwater upwelling leading to spring deposit precipitation and/or mud volcano deposition has been proposed by Rossi et al. (2008), Allen and Oehler (2008), Oehler and Allen (2010), Pondrelli et al. (2011a), and Franchi et al. (2014).

A compositional constraint was provided by the spectral data coming from Observatoire pour la Minéralogie, l'Eau, les Glaces, et l'Activité (OMEGA) (e.g., Bibring et al., 2005) on board the ESA Mars Express mission and from Compact Reconnaissance Imaging Spectrometer 
for Mars (CRISM) on board the NASA Mars Reconnaissance Orbiter (MRO) (Murchie et al., 2007). Monohydrated and/or polyhydrated sulfates, suggestive of acidic conditions, have been detected at several ELDs (Gendrin et al., 2005; Bibring et al., 2006; Mangold et al., 2008; Murchie et al., 2009).

This work focuses on the ELDs located in Arabia Terra (Fig. 1A) and in particular on the area of Firsoff crater and the adjacent plateau (Fig. 1B).

Arabia Terra consists of heavily cratered Noachian plains partially covered by Hesperian material interpreted as low-viscosity lava (Scott and Tanaka, 1986). It connects the highlands and the lowlands of Mars with relatively low slopes $\left(<3^{\circ}\right.$ with the exception of the crater-related slopes) over a wide area $(2500 \times 3600 \mathrm{~km})$ (Smith et al., 1999).

Here ELD formation has been related to a sedimentary basin (Dohm et al., 2007) with a groundwater-dominated hydrological system (Andrews-Hanna et al., 2007, 2010; AndrewsHanna and Lewis, 2011; Zabrusky et al., 2012). Additionally, fluid expulsion-related processes have been increasingly invoked to explain the formation of some pitted cones and mounds within the light-toned deposits in Arabia Terra (Allen and Oehler, 2008; Rossi et al., 2008; Pondrelli et al., 2011a; Franchi et al., 2014). Light-toned deposits in McLaughlin crater analyzed with CRISM data, in the topographically most depressed part of Arabia Terra, show evidence of Fe-Mg-smectite and possibly serpentine and carbonates (Michalski et al., 2013a). Michalski et al. (2013a) interpreted these deposits as formed by alkaline fluids in a lake fed by groundwater upwelling. They claimed that groundwater activity might have occurred at a small scale, locally heterogeneous, rather than as global or regional processes (AndrewsHanna et al., 2007, 2010; Andrews-Hanna and Lewis, 2011) that have been invoked to explain overall "sulfate-ELD" deposition.

In the adjacent Meridiani Planum, the fluid chemistry has been inferred to have been acidic (Tosca et al., 2005); however, the presence of smectites in the lower portions of the stratigraphic column (Arvidson et al., 2014) suggests at least partial formation under higherpH conditions (Wiseman et al., 2010). A hydrological cycle that drives groundwater upwelling requires surface temperatures to be above freezing for long periods of time in order to facilitate precipitation-induced recharge of the aquifers and subsequent evaporation.

Hydrothermal activity that may be associated with volcanic activity interacting with groundwaters, cryosphere or related to impact crater formation has also been invoked as a pos- sible control to explain ELD composition (e.g., Bishop et al., 2009).

Moreover, ELDs in Arabia Terra are particularly intriguing because they are documented both as crater bulges (Newsom et al., 2003; Allen and Oehler, 2008; Lewis et al., 2008; Pondrelli et al., 2011a) and in the plateau (Edgett and Malin, 2002), which may imply a complex geological history and significant process variability.

We selected the study area (longitude $7.1^{\circ} \mathrm{W}-10.7^{\circ} \mathrm{W}$, latitude $3.9^{\circ} \mathrm{N}-0.9^{\circ} \mathrm{S}$ ) of Firsoff crater and the surrounding plateau (Figs. 1A, 1B) because here ELDs can be observed and are well exposed both in the craters and in the plateau (Edgett and Malin, 2002; Pondrelli et al., 2011a). According to Scott and Tanaka (1986), this area displays the geological context required to reconstruct the stratigraphic framework spanning a significant part of Mars geological history (Fig. 1C). The Noachian cratered unit (Npl1) and subdued crater unit (Npl2) of the plateau sequence, which represent the base of the stratigraphic sequence, are covered by the Hesperian ridged plains material (Hr) (Scott and Tanaka, 1986). These units might help in considering the ELDs in a wider stratigraphic context.

In addition, this area has good data set coverage, with full coverage from High Resolution Stereo Camera (HRSC) on board Mars Express (Neukum et al., 2004; Jaumann et al., 2007) and Context Camera (CTX) on board MRO (Malin et al., 2007) and good coverage from CRISM and High Resolution Imaging Science Experiment (HiRISE) on board MRO (McEwen et al., 2007), including several stereo pairs (Fig. 1D).

We reconstructed the stratigraphic framework of the study area and constrained the depositional age of the ELDs. Subsequently, we evaluated the depositional geometries of the ELDs inside and outside the craters. The morphologies, textures, sedimentary structures, and compositional characters of the ELDs were analyzed to infer the depositional processes and emplacement environments. The resulting interpretation is discussed in the context of the regional geology and with regard to the possible implications in terms of habitability.

\section{DATA AND METHODS}

Data from Mars Express HRSC, MRO CTX, and MRO HiRISE have been processed using the JPL/DLR (Jet Propulsion Laboratory/ Deutsches Centrum für Luft- und Raumfahrt). Video Image Communication and Retrieval (VICAR) environment software for HRSC data, and the Integrated Software for Imagers and Spectrometers (ISIS) provided by the U.S.
Geological Survey (Anderson et al., 2004) for CTX and HiRISE data. All data were integrated in ESRI ArcGIS software.

We produced a detailed geological map at a mapping scale of 1:50,000 in order to constrain the ELDs' vertical and lateral stratigraphic framework and depositional geometries. In order to provide timelines to our reconstructions, we derived absolute ages using crater-size frequency analyses. Craters were counted in individual geologic units over the whole diameter size using the CraterTools extension for ESRI ArcGIS software in order to minimize distortions introduced by map projections (Kneissl et al., 2011). Absolute model ages were determined using the software Craterstats (Michael and Neukum, 2010) applying the Mars production function of Ivanov (2001) and the chronology function of Hartmann and Neukum (2001). Additionally, Craterstats cluster analyses were performed to avoid measuring in areas with contamination by secondary craters (Michael et al., 2012; Michael, 2013). Plots shown here present impact-crater size distributions with frequencies as a function of sizes in their established cumulative form. It has, however, been shown that differential plots are well suited to distinguish resurfacing events quite unambiguously, and we used these displays for data assessment (Michael, 2013).

Digital elevation models (DEMs) based on CTX and HiRISE data were computed using the NASA Ames Stereo Pipeline (ASP) suite (Broxton and Edwards, 2008; Moratto et al., 2010). CTX and HiRISE data sets were corrected to the areoid. The resulting DEMs are tied with the regional HRSC mosaic (tied and bundleadjusted to MOLA [Mars Orbiter Laser Altimeter] itself). The $z$ uncertainties were qualitatively and semiquantitatively assessed by comparing them with HRSC data and each other and using the intersection alignment error output from ASP for individual DEMs. Three-dimensional visualization and analyses were made using the software QPS Fledermaus. Layer attitudes were measured using the software Orion from Pangaea Scientific.

MRO's instrument CRISM provided hyperspectral data that were processed using the software CAT (CRISM Analysis Toolkit; Morgan et al., 2014), produced by the CRISM Science Team, which runs as an extension to ENVI software (Exelis VIS). The spectral parameter maps were computed using the spectral parameter summary products described in Pelkey et al. (2007).

The geological map was made using the available data set, but was mapped at CTX scale (i.e., 1:50,000), with the aim to integrate geological and geomorphological approaches. 

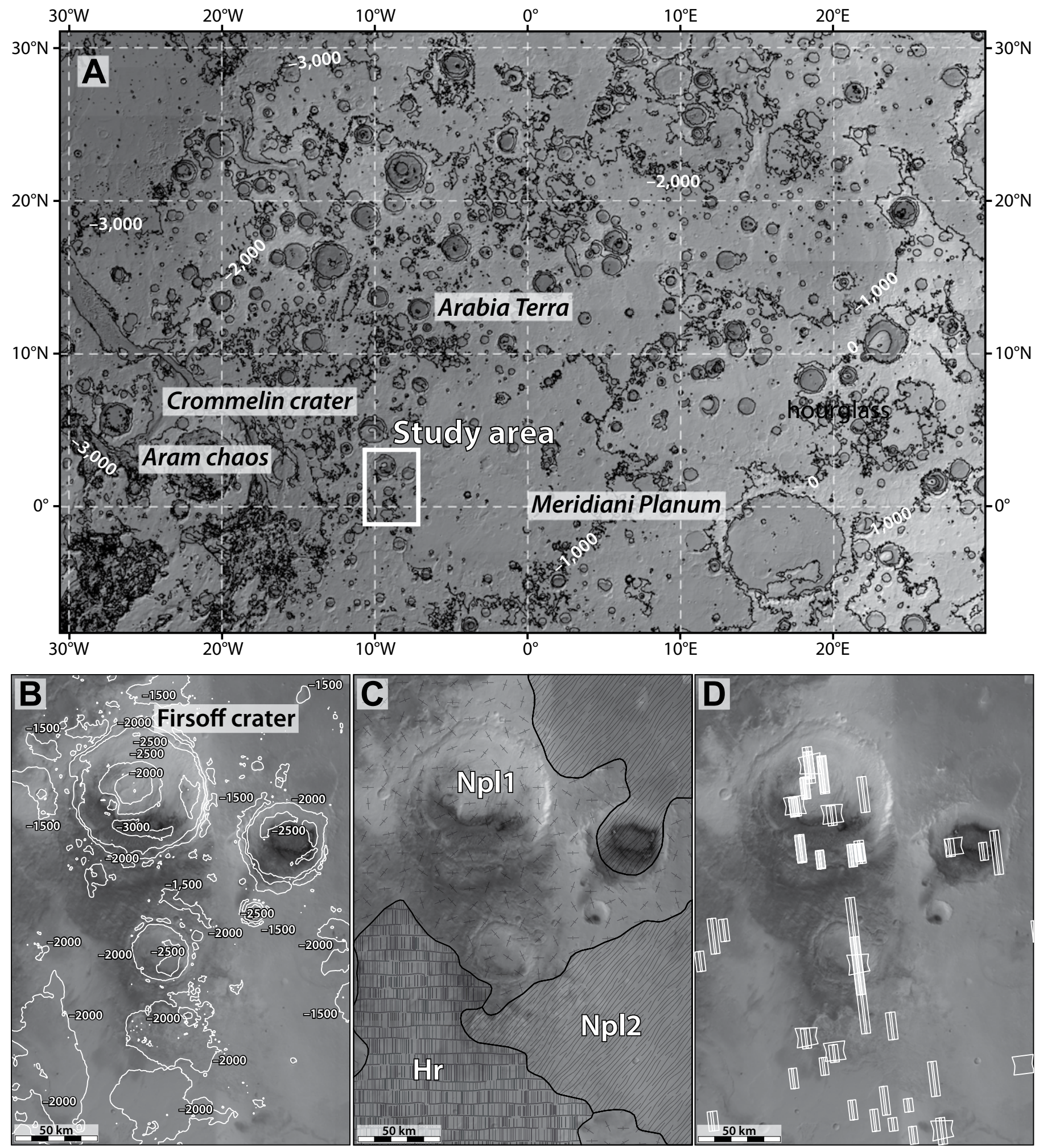

Figure 1. (A) Location map of the study area on MOLA-based shaded relief map. Topographic contours (in black, $1000 \mathrm{~m}$ spacing) are indicated. (B) High Resolution Stereo Camera (HRSC) mosaic of the mapped area. Topographic contours (in white, $500 \mathrm{~m}$ spacing) are indicated. (C) Excerpt of the geological map by Scott and Tanaka (1986) on an HRSC mosaic. Geologic units (see text for more details): Npl1-Noachian cratered unit of the plateau sequence; Npl2-Noachian subdued crater unit of the plateau sequence; Hr-Hesperian ridged plains material. (D) Footprints of High Resolution Imaging Science Experiment (HiRISE) coverage on an HRSC mosaic. The white filling indicates stereo pairs. The area is fully covered by Context Camera (CTX) imagery. Compact Reconnaissance Imaging Spectrometer for Mars (CRISM) scenes used in this study are recognizable by the hourglass shape. 
Accordingly, in defining the units, we tried to merge the information on the characteristics of the deposits (e.g., layered versus non-layered, albedo, texture, sedimentary structures, hints on composition where possible) together with their morphological characters both at regional (e.g., depositional geometries such as crater bulges, etc.) and more detailed (e.g., dunes, raised rims, etc.) scale. The position within the stratigraphic succession, defined using relative stratigraphy and constrained by crater-counting analysis, has also been a key to distinguish the units. All of this information was listed in an attribute table, so that a unit is defined by common deposits (e.g., high albedo, medium rough texture, layering, meter-scale polygonal pattern) showing the same morphologies at regional (e.g., located within a crater bulge) and at local scale (e.g., raised rims, circular depressions) and located in the same stratigraphic position within the succession (e.g., nonconformably on top of the plateau sequence and disconformably below the hummocky material).

No genetic interpretations on the units have been included in the unit identification in order to make the geological map as objective as possible.

\section{GEOLOGICAL SETTING}

Our geological map of the study area (Fig. 2) enabled us to identify the lateral and vertical relations between the geological units and allowed us to eventually reconstruct the stratigraphic framework (Fig. 3).

The basement units of the stratigraphic succession of the area are the cratered unit and the subdued crater unit of the plateau sequence (Scott and Tanaka, 1986). The cratered unit consists of massive, although commonly fractured, medium-albedo material. Locally it shows sharp edges which suggest a strong resistance to weathering; it also appears locally as smooth or rugged, thus suggesting a variety of emplacement processes. The cratered unit is primarily found at the crater rims (Fig. 2).

According to Scott and Tanaka (1986), the cratered unit formed during the period of high impact flux and are thus heavily cratered. It represents a mixture of lava flows, pyroclastic material, and impact breccia. This unit is covered by the subdued crater unit, which shows similar characteristics as the cratered unit, although darker toned and smoother. This unit embays the older cratered unit, partially filling the craters, which suggests that it formed after these craters were emplaced, which in turn implies that a nonconformity separates the two units (Scott and Tanaka, 1986). Scott and Tanaka (1986) interpreted the subdued cra- ter unit as interbedded lava flows and aeolian deposits that partly bury the underlying cratered unit.

ELDs rest nonconformably on top of both units of the plateau sequence (Figs. 2 and 3). Both within and between craters, ELDs tend to drape and onlap the basements units. Inside Firsoff crater, ELDs are shown to postdate the cratered unit and to onlap the crater ridges (Fig. 4A), thus suggesting infilling of the basin. Their layer attitude, which will be discussed in the following sections, suggests that ELDs drape the plateau, adapting to the pre-existing topography (Figs. 4A, 4B).

ELDs consist of distinctly to faintly layered light-toned deposits locally interlayered with layers of dark-toned material. In general, they show the characteristic pattern of the etched terrains as described in Meridiani Planum (e.g., Hynek et al., 2002). More in detail, their characteristics change substantially from the craters to the plateau (Table 1).

The depositional architecture in the craters consists of bulges which reach thicknesses of $>2000 \mathrm{~m}$. On the plateau ELDs form sheet drapes. Locally, inside as well as outside the craters, mounds with diameters of a few hundred meters are associated with the well-bedded ELDs. These differences in morphology, detailed below, were used to distinguish subunits among ELDs (Fig. 2).

ELDs are unconformably overlain, both inside and outside of craters, by a layered to faintly layered unit that we informally named "hummocky material" (Figs. 4B, 5A, 5B). The unconformable contact is suggested by the fact that the dark-toned deposits of the hummocky material irregularly drape different ELD layers (Figs. 5A, 5B). The hummocky material consists of dark-toned and relatively smooth material forming slightly irregular surfaces with undulations at all scales but mostly characterized by long wavelengths (up to kilometers). This unit appears to be resistant to weathering and erosion, showing at places sharp edges and boundaries. Where eroded, the resulting material appears to be reworked by wind to form aeolian dunes. The hummocky material covers the previously deposited plateau sequence and ELDs, preferentially, but not exclusively, occupying topographic lows. Although more detailed analyses would be necessary to properly interpret the genesis of the hummocky material, the general character (ubiquitous distribution inside and outside craters, general wavy appearance) appears to be consistent with deposition through pyroclastic processes, possibly including pyroclastic surges.

In the southernmost part of the study area in the plateau, the ELDs and the hummocky mate- rial are unconformably covered by the ridged plains material. The ridged plains material consists of broad, flat and rough surfaces very resistant to weathering and erosion, with flow lobes visible in places and long, parallel, linear to sinuous wrinkle ridges. On the basis of such characteristics and due to the unit's widespread geographical distribution, it has been interpreted as extensive flows of low-viscosity lava erupted from several sources at high eruption rates (Scott and Tanaka, 1986).

The youngest deposits of the area consist of mass-wasting materials along the slopes, and aeolian dust and dunes made up of dark-toned sediments draping the older parts of the succession. Aeolian processes also produced erosional features, forming yardangs through incision of the ELDs (Fig. 2). In some areas the exposed surface is unconformably covered by a blanket of dark-toned material which is probably the result of a mix of different processes, including weathering, to form regolith (e.g., Sullivan et al., 2011). This material is indistinguishable from and probably mixed with later dust deposition, and has been mapped as the generic unit "mantling" (Fig. 2).

A lower bound of the deposition age of the cratered unit has been estimated by performing crater counts on the Firsoff crater ejecta (Fig. $6 \mathrm{~A})$. For an area of $2.62 \times 103 \mathrm{~km}$ we counted 174 craters in the diameter range of $0.1-7.2 \mathrm{~km}$. These data yielded an estimated emplacement model age as old as $3.67^{+0.06 /-0.10}$ Ga or even older (Fig. 6B), corresponding to a late Noachian age, according to the size-frequency distribution of Hartmann (2005) (Fig. 3). The size-frequency distribution bends over at diameters of $300 \mathrm{~m}$ and less and shows a pronounced kink that seems to indicate that the cratered unit underwent a resurfacing event as late as $2.82^{+0.32} /-0.46 \mathrm{Ga}$ (Fig. $6 \mathrm{~B})$, which corresponds to an early Amazonian age (Hartmann, 2005; Michael, 2013) (Fig. 3). A resurfacing process appears to be consistent with the geological context and the morphologies of the craters, but it cannot be excluded by statistical data alone that it might have occurred through a long-term removal of smaller craters not related to a single specific event. The hummocky material disconformably covers the ELDs inside (Fig. 5B) and outside (Fig. 5A) Firsoff crater. Both ELDs and hummocky material drape the older deposits of the plateau sequence, possibly concealing some craters. Also, more recent deposits such as aeolian dust might have concurred in the resurfacing process, which might have occurred as a relatively continuous process in the geological record. The deposition of these units might likely represent the cause of at least part of the resurfacing event(s) which possibly occurred as late as $2.82^{+0.32} /-0.46$ Ga (Fig. 6B). 


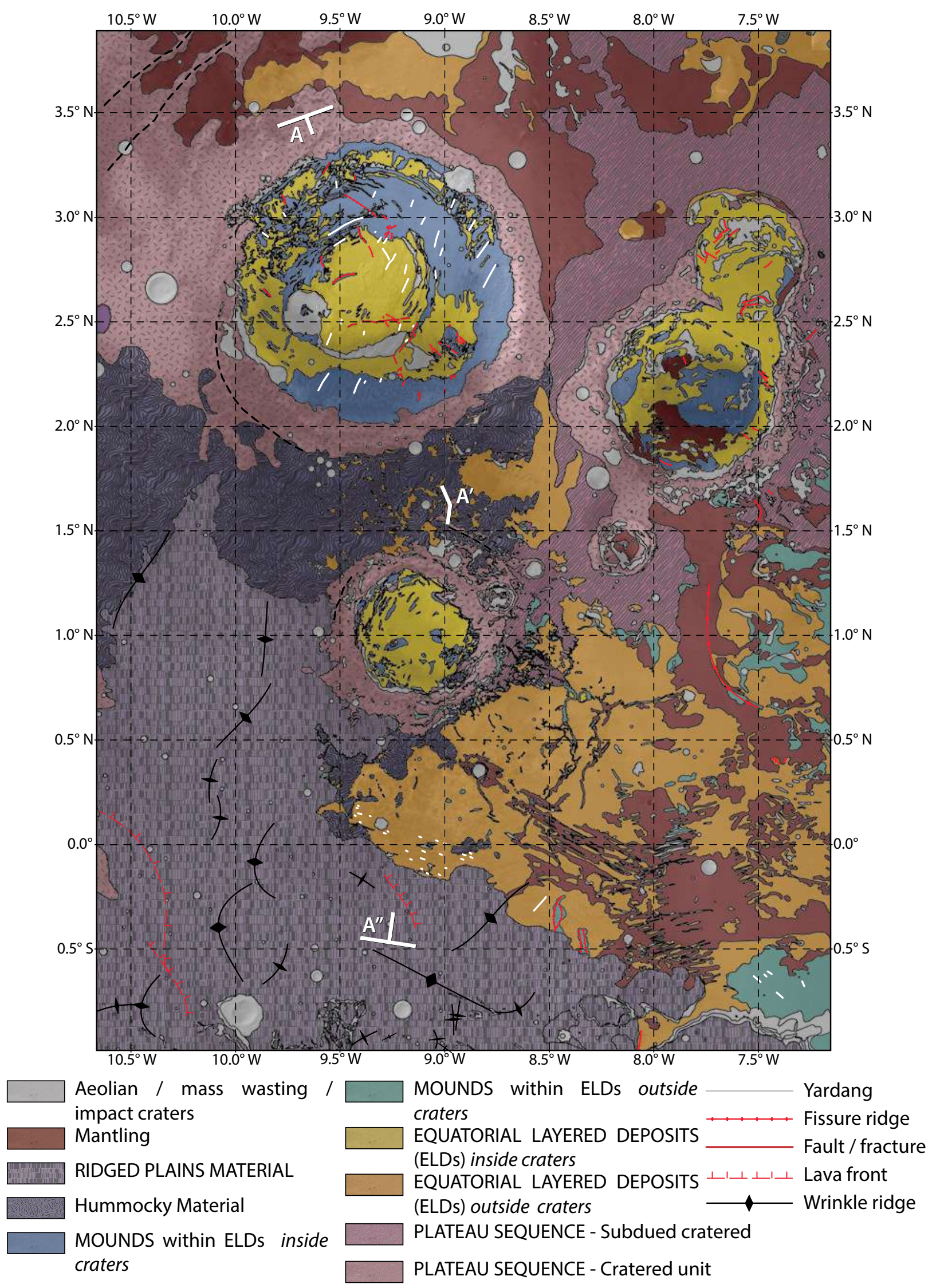

Figure 2. Geological map of the study area. $A-A^{\prime}-A^{\prime \prime}$ represents the trace of the geological section shown in Figure 3. 


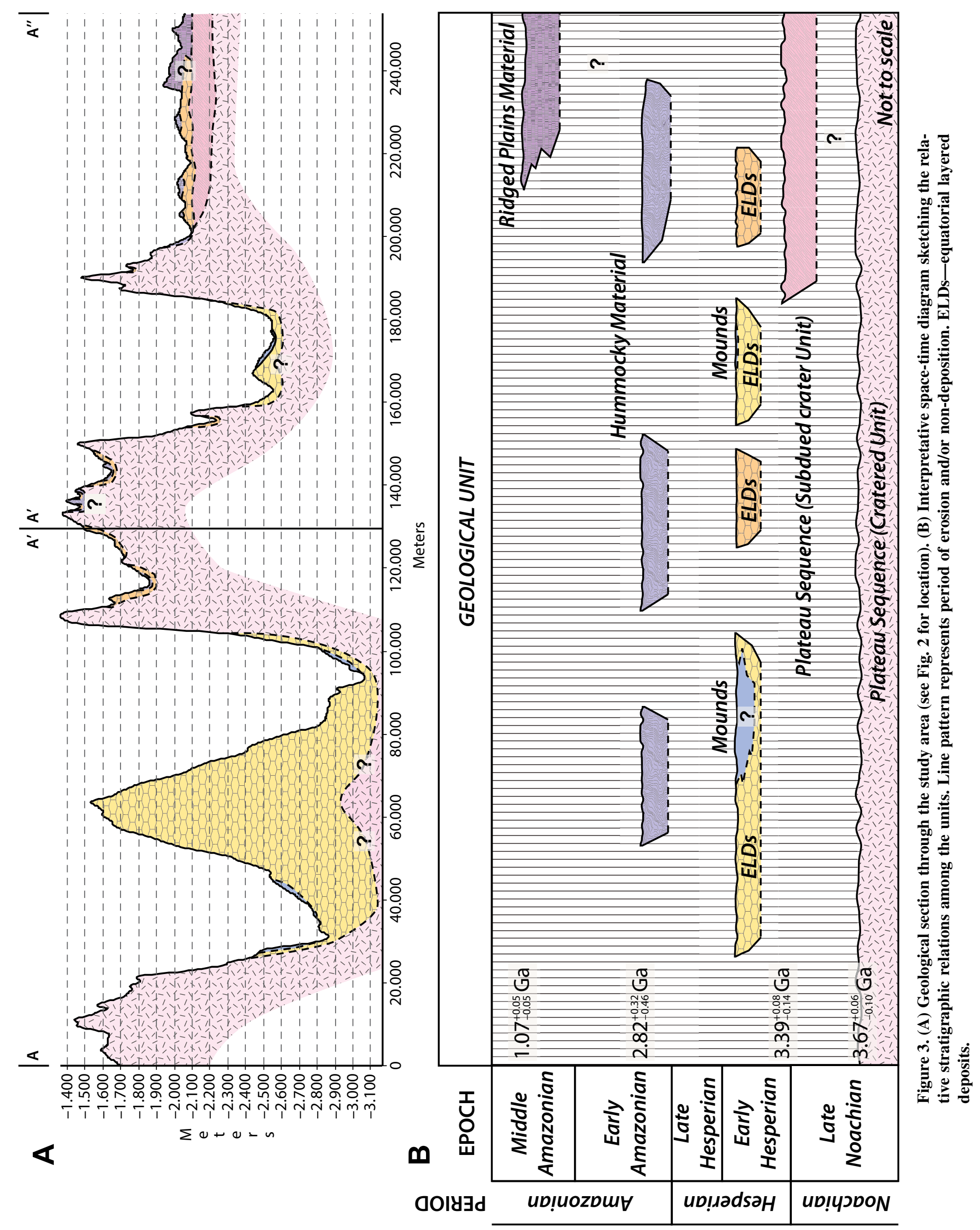



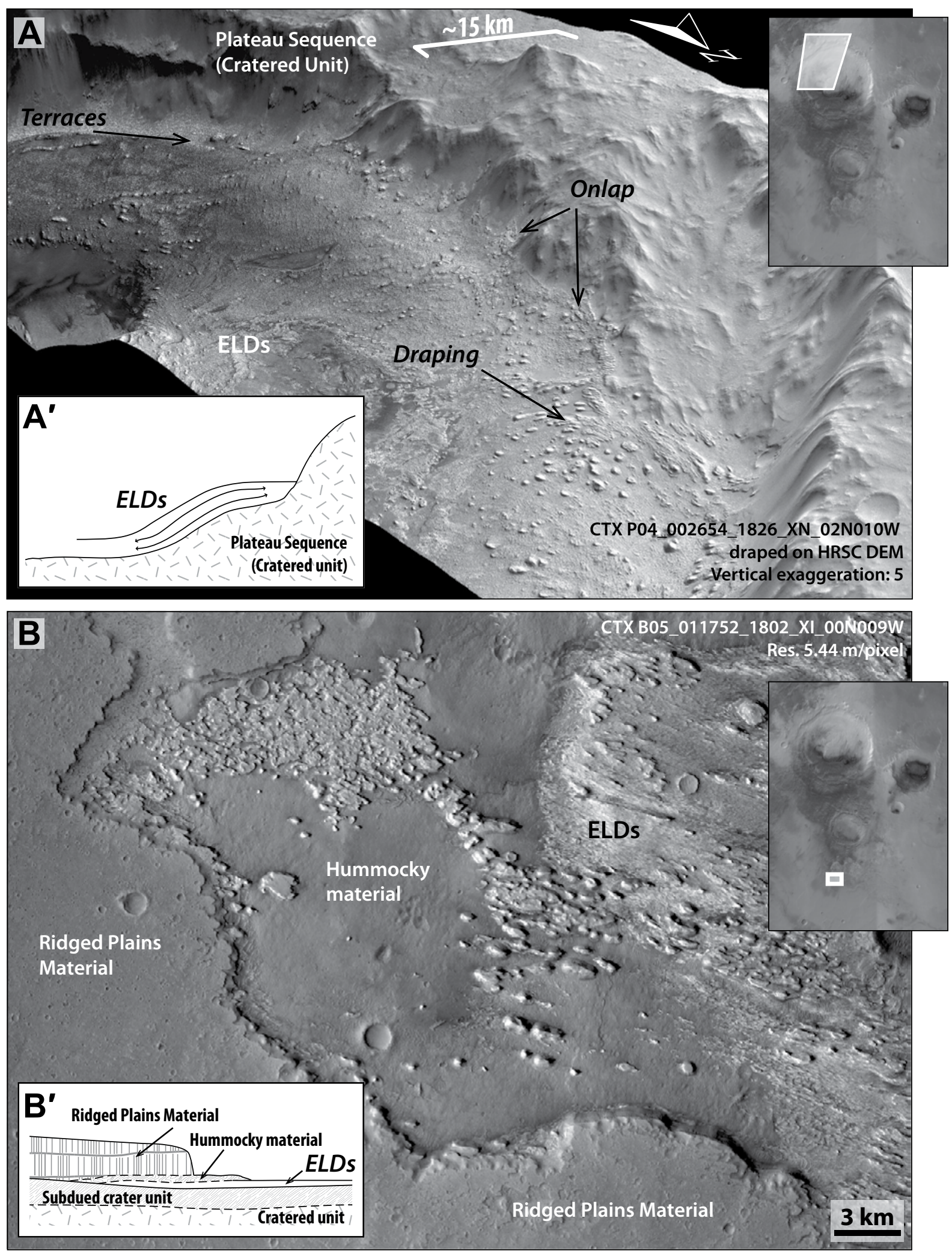

Figure 4. Stratigraphic relations of the equatorial layered deposits (ELDs). (A) Three-dimensional image showing ELD layers that drape and onlap the deposits of the plateau sequence (cratered unit). Location of the image is indicated in the top right HRSC mosaic. Stratigraphic relations and geometries are sketched in the inset $\left(A^{\prime}\right)$. (B) ELDs covered by younger hummocky material and ridged plains material. Location of the image is indicated in the top right $\mathrm{HRSC}$ mosaic. Stratigraphic relations and geometries are sketched in the inset $\left(B^{\prime}\right)$. 
TABLE 1. SUMMARY OF THE CHARACTERISTIC FEATURES OF THE EQUATORIAL LAYERED

DEPOSITS (ELDS) FOUND IN THE CRATERS AND IN THE PLATEAU, ARABIA TERRA, MARS

\begin{tabular}{|c|c|c|c|c|c|}
\hline Setting & \multirow{2}{*}{\multicolumn{2}{|c|}{ Crater }} & \multicolumn{3}{|c|}{ Plateau } \\
\hline $\begin{array}{l}\text { Architecture of the } \\
\text { ELDs }\end{array}$ & & & \multicolumn{3}{|c|}{ Sheet drapes } \\
\hline Stratal pattern & \multicolumn{2}{|l|}{ Draping, onlapping } & \multicolumn{3}{|c|}{ Draping, onlapping } \\
\hline Units & Layered unit & Mounds & Mounds & $\begin{array}{l}\text { Flat-lying bedded } \\
\text { to faintly bedded } \\
\text { deposits }\end{array}$ & $\begin{array}{l}\text { Bedded deposits } \\
\text { associated with } \\
\text { dune fields }\end{array}$ \\
\hline $\begin{array}{l}\text { Textures and } \\
\text { sedimentary structures }\end{array}$ & Layering; polygonal pattern & $\begin{array}{r}\text { Layering; } \\
\text { breccia }\end{array}$ & Uncertain & $\begin{array}{l}\text { Layering; polygonal } \\
\text { pattern }\end{array}$ & Layering; cross-bedding \\
\hline Morphologies & $\begin{array}{l}\text { Fissure ridges; etched terrains; dish-shaped depressions, } \\
\text { raised rims, bowl-shaped appearance; serrated layer } \\
\text { morphology }\end{array}$ & $\begin{array}{l}\text { Pitted cones; } \\
\text { fissure ridges }\end{array}$ & $\begin{array}{l}\text { Conical shape; } \\
\text { pitted? }\end{array}$ & $\begin{array}{l}\text { Flat bodies; etched } \\
\text { terrains*; fissure } \\
\text { ridges }\end{array}$ & Dune fields \\
\hline
\end{tabular}

Our data do not allow distinguishing the probably various phases of resurfacing events, but $2.82^{+0.32} /_{-0.46}$ Ga would mark the last event (emplacement of the last deposits of the hummocky material) and thus postdate ELDs deposition.

The deposition age of the units on the plateau, in the southernmost part of the study area, has been estimated using crater-size frequency analyses in the area outlined in Figure 6C. We counted 3495 impact craters in the diameter range of $0.04-4.0 \mathrm{~km}$ in a counting area of $12,734 \mathrm{~km}^{2}$. Data were fitted down to a diameter size of $300 \mathrm{~m}$, where the distribution bends over toward smaller craters. The distribution does not show pronounced kinks but a general flattening near the $1 \mathrm{~km}$ diameter size indicating continuous erosion. Analyses resulted in a well-constrained emplacement age for the plateau units of $3.39^{+0.08} /{ }_{-0.14} \mathrm{Ga}$ and a resurfacing age of $1.07^{+0.05} /-0.05 \mathrm{Ga}$ (Fig. 6D). In the plateau, the subdued crater unit is covered by the ridged plains material (Figs. 2, 4B) which embays and partially conceals the older morphologies. So in

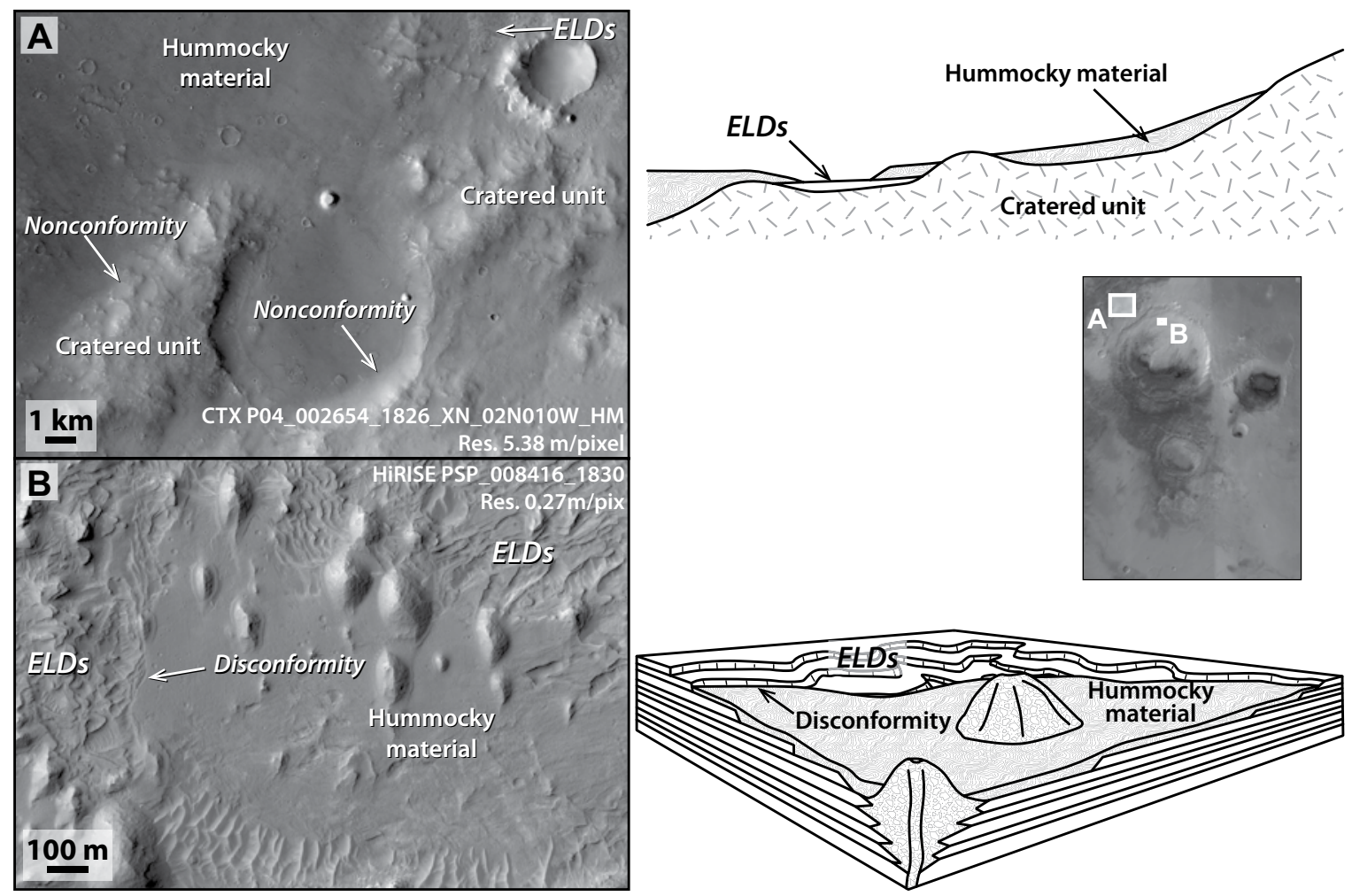

Figure 5. Stratigraphic relations. (A) CTX image showing the stratigraphic relations between the cratered unit, the equatorial layered deposits (ELDs), and the hummocky material north of Firsoff crater (see the HRSC-based mosaic located at the center right of the figure for location). The hummocky material stays in nonconformity on top of the cratered unit and in disconformity on top of the ELDs. Stratigraphic relations and geometries are sketched to the right of the image. (B) HiRISE image showing the stratigraphic relations between the ELDs and the hummocky material inside Firsoff crater (see the HRSC-based mosaic located at the center-right of the figure for location). ELDs consist of layers and mounds and are covered in disconformity by the hummocky material. Stratigraphic relations and geometries are sketched in the block diagram to the right of the image. 

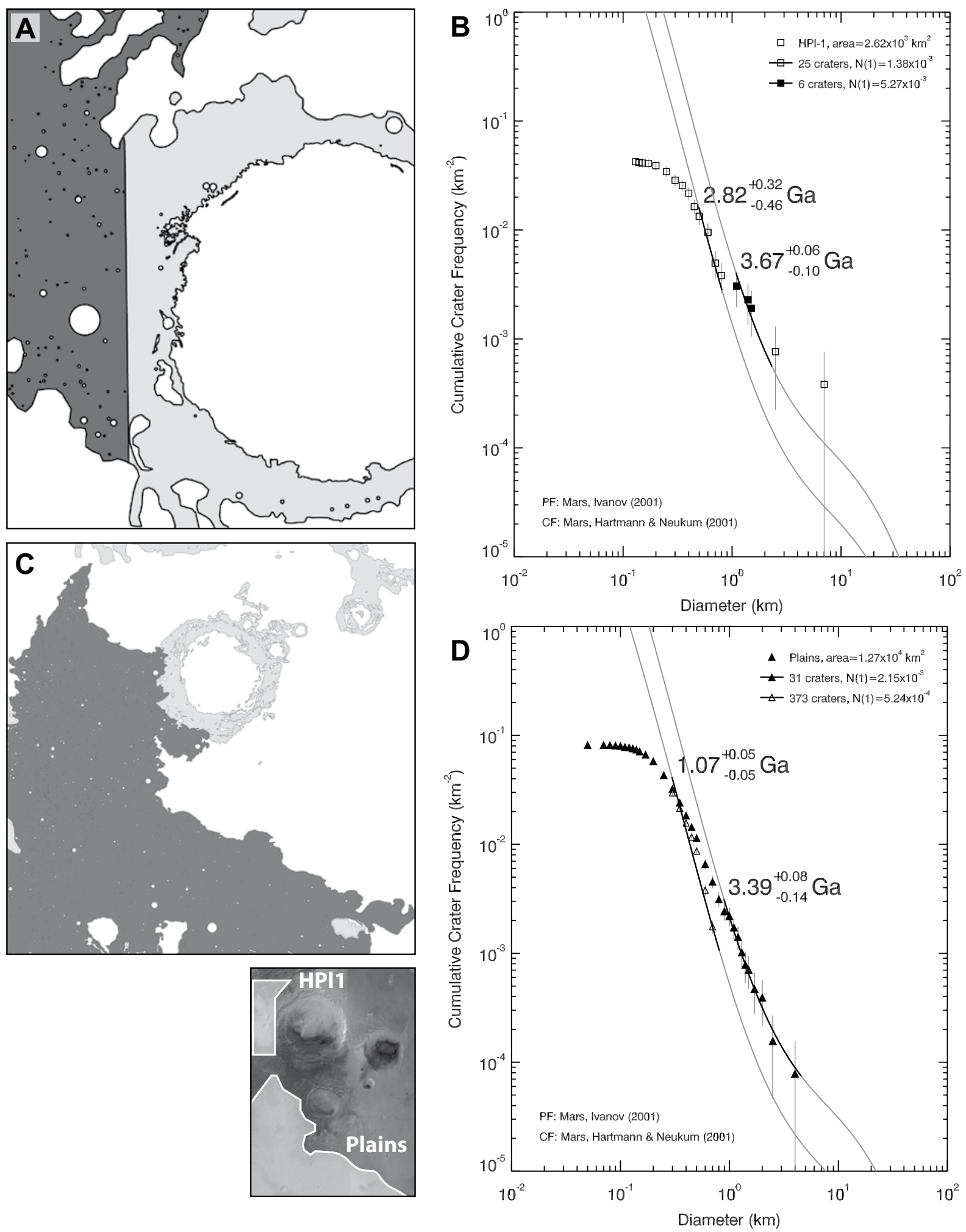

Figure 6. Crater size-frequency distribution results. (A) Excerpt of the geological map (see Figure 2) with the area where crater size frequency measurements have been performed in unit HPI1 (Plateau sequence, cratered unit) outlined in dark gray (see the HRSC mosaic at lower left for location). (B) Crater size-frequency measurements of the area shown in A. (C) Excerpt of the geological map with the area where crater size frequency measurements have been performed in the plains outlined in dark gray (see the HRSC mosaic at lower left for location). (D) Crater size-frequency measurements of the area shown in C. Isochrones in B and D are plotted based upon the crater chronology model (CF) of Hartmann and Neukum (2001) and production function coefficients (PF) of Ivanov (2001). See text for discussion. N(1)—sum of all craters $D \geq 1 \mathrm{~km}$ on a given unit. 
places, even where the unit present and mapped is the ridged plains material, the mapped and counted craters were emplaced on the subdued crater unit. Accordingly, we interpret the $3.39^{+0.08} /-0.14$ Ga age as lower bound of the depositional age of the subdued crater unit and the $1.07^{+0.05} /-0.05 \mathrm{Ga}$ age as the depositional age of the uppermost portion of the ridged plains material.

Relative stratigraphy and crater counting data are summarized in the space-time diagram of Figure 3. According to these data, the plateau sequence would have been deposited until the late Noachian, with an evident, although unquantifiable, nonconformity between the cratered unit and the subdued crater unit. ELD deposition would be constrained between the Noachian-Hesperian transition and the lower part of the early Amazonian, postdated by the hummocky material deposition. The ridged plains material was deposited until the middle Amazonian, closing the stratigraphic succession of the study area with the exception of the most recent aeolian dust and dune deposition and regolith formation.

\section{EQUATORIAL LAYERED DEPOSITS: GEOMETRIES}

ELDs mapped inside and outside craters (Fig. 2) show the same basic character: faint to well-developed layering and high albedo. However, ELDs exhibit different depositional geometries depending on their location (Fig. 7A; Table 1). ELDs form a kilometer-thick crater bulge inside Firsoff crater but exist as patches on the plateau (sheet drape shape) where they are irregular and rough at the scale of hundreds of meters but relatively flat at regional scale (Fig. 7B).

On the inner rim side of Firsoff, ELDs reach and cover the terraces related to the crater formation, located $400 \mathrm{~m}$ above the crater floor (Fig. 4A). No ELDs are found above that level. Using equations derived by Garvin et al. (2003) and assuming a simple ballistic impact, the geometry of the impact crater and therefore the thickness of the sedimentary infilling can be (indirectly) estimated (Franchi et al., 2014; Lucchetti et al., 2014). In this case, the greatest thickness of the crater infill reaches $\sim 2 \mathrm{~km}$ roughly on top of the central peak, whereas the thickness of sedimentary infill relative to the bulk of the crater floor was estimated to reach as much as $1.2 \mathrm{~km}$. We acknowledge that these numbers are approximations because it is possible to quantify neither the effects of erosion nor the amount of materials (e.g., aeolian dust or dunes) deposited below the ELDs. Our aim is merely to infer the order of magnitude of the scale of the sedimentary body and its geometry as a whole.

On the plateau next to Firsoff crater, ELDs do not form kilometer-thick mounds. They appear to drape the older plateau more or less homogeneously as a sheet drape, although irregularities exist at smaller scales (Figs. 7A, 7B). No complete section allows us to estimate the overall thickness of ELDs on the plateau, but the available exposures are at most $10 \mathrm{~m}$ thick based on the CTX DTM (Digital Terrain Model).

\section{ELDS WITHIN CRATERS}

ELDs are heavily eroded by aeolian activity as shown by the widespread presence of yardangs which occur especially, although not exclusively, in the topmost part of the bulge of ELDs in Firsoff crater. Here, the depositional morphology of ELDs is obscured by the younger erosional landforms (Fig. 8A). The presence of such features implies that ELDs are made of relatively easily erodible material and that the original depositional geometry is at least partly destroyed by the erosion. However, especially on the crater floors, most of the ELDs appear to be largely unaffected by aeolian erosional modification (Figs. 8A, 8B). In these locations, ELD layers show rounded shapes or occasionally raised margins (Fig. 8C), and lengthen irregularly in directions that are not consistent with a formation as erosional remnant resulting from wind action (Figs. 8B, 8C). Moreover, their orientation is unrelated to wind direction as inferred from yardangs (Fig. 8B). ELDs here are sinuous and rounded, locally showing quasi-circular depressions locally bounded by elevated rims.

Figure 8D shows a northwest-southeasttrending depression that is lens shaped in plan view and displays a regularity and trend that seems to be unrelated to wind erosion as inferred from yardangs. Moreover, this depression is characterized by mounds (tens to hundreds of meters wide) aligned along elevated lineaments (Fig. 8D; possible fissure ridges), both indicating a depositional origin. The presence of rounded shapes, locally raised margins, quasicircular depressions, and possible fissure ridges with aligned mounds suggests that in those areas the ELD morphology was not affected by post-depositional erosion strong enough to conceal their original morphology. On the basis of these observations, we suggest that at least part of the ELD morphologies are depositional, or that they cannot be attributed only to aeolian erosion. Instead, in different places the presence of yardangs proves the action of an aeolian erosional activity strong enough to obliterate the original morphological character.
For preservation of the depositional morphologies in the bulge of ELDs in Firsoff, either the bulge must represent the product of differential erosion that was able to exhume older preserved landforms, or it must be the original depositional landform with the exception of the post-depositional erosion emphasized by the yardangs. Desiccated fine-grained materials (i.e., clay and/or silt sized) might be relatively easily eroded by wind action. This has been considered as a likely process leading to the exhumation of clay-embayed bodies such as channels in Miyamoto (Newsom et al., 2010) and Eberswalde craters (Pondrelli et al., 2011b). Nevertheless, in our study area there is no evidence that might support the presence of different lithologies (i.e., fine-grained materials easily eroded by wind) that could explain differential erosion and exhumation of older preserved morphologies. Yardangs do not appear to selectively affect particular stratigraphic levels. ELDs show, at the available resolution, common characteristics that do not support the hypothesis of a significant difference in the lithological composition.

As a consequence, we suggest that the ELDs never filled the crater entirely and that the current bulge morphology, although affected by some post-depositional erosion, represents the remnant of a depositional geometry.

ELDs in Firsoff and other craters consist of two informal units, which potentially might be formalized as formations: a layered unit and mounds (Figs. 2, 9A, 10A). These units are defined based on their sedimentological (texture and structure at the scale of the available resolution) and morphological character.

The layered unit consists of light-toned meter-scale layered material locally probably interlayered with dark-toned layers, disrupted in a polygonal pattern (Fig. 10B). The polygons are on average about 3-4 $\mathrm{m}$ in diameter. Polygons of this scale and morphology (i.e., where a periglacial origin can be excluded both by the morphology of the features themselves and by the lack of associated periglacial landforms) are very widespread on Mars and have been associated with potential desiccation cracks (Schieber, 2007; El-Maarry et al., 2013, 2014), post-depositional cementation in sulfate sand followed by contraction due to dehydration (Chavdarian and Sumner, 2006), or post-depositional weathering (Chan et al., 2008). Whatever their genesis, the polygonal features overprint the original sedimentary structures.

Layers generally gently dip $\left(<10^{\circ}\right)$ and drape the older crater deposits (Figs. 4B, 9A, 9B). Higher dip values (still not exceeding $20^{\circ}$ including possible measurement errors) are found in correspondence to the steeper parts close 
A

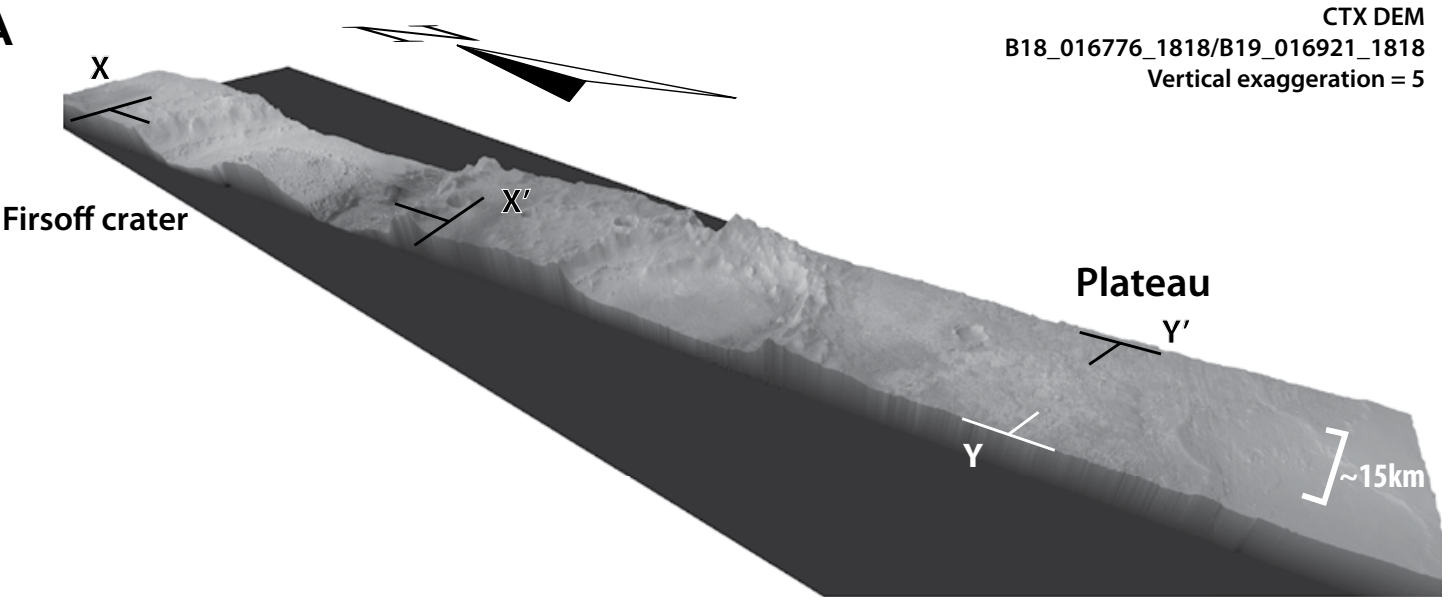

\section{B}

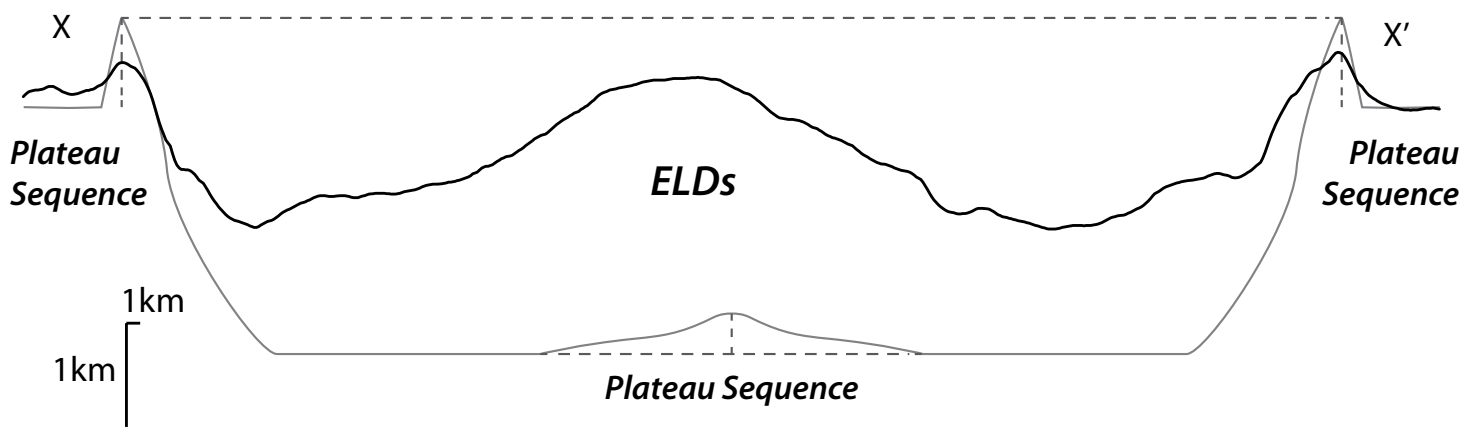

Y

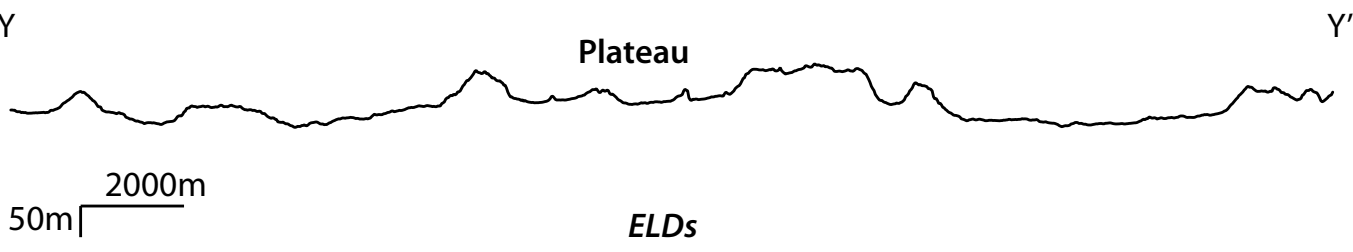

Figure 7. Geometries of the basins. (A) CTX-based three-dimensinoal view across part of the study area with the trace of the profiles shown in B. (B) HRSC-derived profile $X-X^{\prime}$ though Firsoff crater and CTX-derived profile $\mathrm{Y}-\mathrm{Y}^{\prime}$ in the plateau. In profile $\mathrm{X}-\mathrm{X}^{\prime}$, the inferred approximate morphology of the crater devoid of equatorial layered deposits (ELDs) and other possible deposits (Garvin et al., 2003) is reconstructed in light gray. See text for description.

to the crater rim (Figs. 9A, 9B, 9C; see GSA Data Repository $\left.{ }^{1}\right)$. At the scale of the available resolution $(25 \mathrm{~cm} /$ pixel) there is no observable evidence of cross-stratification or other sedimen-

${ }^{1}$ GSA Data Repository item 2015095, table showing the parameters associated to layer attitude measurements including latitude, longitude, strike, dip, relative errors and goodness of fit, is available at http://www.geosociety.org/pubs/ft2015.htm or by request to editing@geosociety.org. tary structures, apart from the polygonal pattern, within the layered unit (Figs. 9C, 10B).

Layers appear to possess a good lateral continuity although their irregularities make it difficult to trace individual layers (Figs. 10D, 10E). Layer irregularities take the form of dish-shaped depressions, raised rims, bowl-shaped appearances, and serrated layer morphology (Figs. $10 \mathrm{D}, 10 \mathrm{E}, 11 \mathrm{~A}, 11 \mathrm{C}$ ). As a consequence, though there is no evidence of major unconformities, it is not possible to exclude the presence of some subtle disconformities and/or paraconformities.

Layer morphologies may represent depositional or alternatively syn- or post-depositional erosional character. We argued that post-depositional aeolian erosion is unlikely. Layers commonly show slightly vertical or sub-vertical synform-like geometries (Fig. 11C), some of which are similar to the ones found in Crommelin crater ("ridge-and-trough"; Franchi et al., 

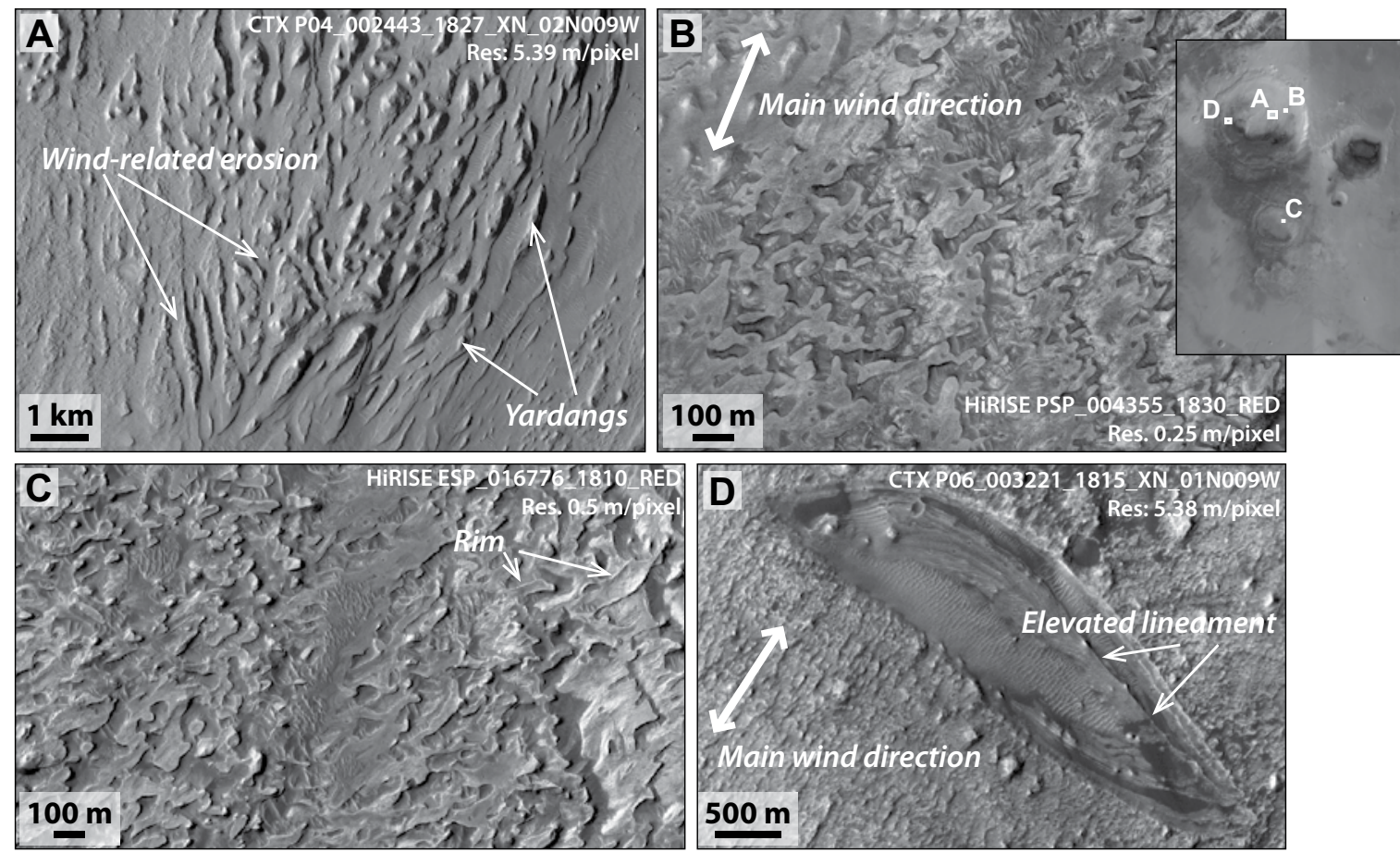

Figure 8. Erosional versus depositional morphologies. (A) Example of aeolian erosion with yardangs on equatorial layered deposits (ELDs). (B) ELD irregularly shaped layers. ELDs show rounded edges and lengthen in a direction and with geometries not consistent with formation by aeolian erosion. Main wind direction as inferred by yardang alignment is indicated at the top left. (C) ELD irregularly shaped layers. Some of the layers are characterized by the presence of rims. (D) Northwest-southeast-trending depression. Its regularity and trend do not seem consistent with an erosional formation by wind action. Main wind direction as inferred by yardang alignment is shown at the bottom left. Inside the depression, elevated lineaments (fissure ridges?), emphasized by mounds, are present. The location of the images is indicated in the HRSC mosaic at the top right of the figure.

2014). However, no antiform-like, recumbent, chevron, or in general tight folds are present, which argues against a slump or tectonic origin for these features.

The rounded margins and shape (Figs. 8B, $8 \mathrm{C}, 10 \mathrm{E}$ ) and the dish-shaped depressions (Figs. $8 \mathrm{~B}, 8 \mathrm{C}, 10 \mathrm{D}, 10 \mathrm{E}, 11 \mathrm{C})$ are very similar to dissolution-related morphologies such as solution pans (Murana and Kneissl, 2014). These morphologies would suggest a possible combination between a depositional control (e.g., higher versus lower depositional rate) and syn- to postdepositional water-related chemical etching.

Exposures of stratigraphic successions in the study area are nowhere thick enough to consistently evaluate the possible presence of a cyclic depositional pattern such as the one investigated in nearby Becquerel crater (Lewis et al., 2008; Lewis and Aharonson, 2014).

ELDs within craters show the presence of rectilinear, probably fracture-controlled, elevated lineaments (Figs. 8D, 11A, 11B). These lineaments are made of the layered unit (Fig. $11 \mathrm{~A}$ ). Their scale is quite variable, ranging from a few hundred meters to several kilometers in length while their height in CTX and/or HiRISE DEMs can be estimated to be some tens of meters. We interpret these features as possible fissure ridges. The presence of fissure ridges would imply sourcing from the subsurface.

Putative fissure ridges are commonly associated with the presence of mounds (Figs. 8D, 11B). The mounds consist of both simple and coalescing conical features. Simple mounds are conical features $100-300 \mathrm{~m}$ in base diameter with sub-circular shapes in plan view, while composite mounds reach up to $500 \mathrm{~m}$ in diameter (Figs. 2, 10A, 10C, 12A, 12B). In HiRISEbased DEMs the height of these edifices ranges from $\sim 30 \mathrm{~m}$ to $120 \mathrm{~m}$ for the simple mounds, but reach up to several hundred meters for the composite mounds (Figs. 12B, 13B, 13C) (Pondrelli et al., 2011a). The mounds are made of bouldersized mixed with finer-grained material, with high-albedo clasts and darker matrix (Fig. 10C) (Pondrelli et al., 2011a).

Mounds in Firsoff crater have been described by Pondrelli et al. (2011a). The mounds are particularly abundant and form clusters of mounds (Fig. 12A) close to the outermost margin of the craters (Figs. 2, 3), especially in the southern margin (Franchi et al., 2014) where rim-related faults and fractures are abundant (Schultz et al., 1982). Mounds are also found, although rarer and scattered, both within and outside the craters (Figs. 2, 3). Mounds are commonly aligned with putative fissure ridges (Figs. 8D, 11B, 13A). The relation between mounds and fissure ridges suggests a possible genetic linkage between the presence of assumed preferential pathways for groundwater upwelling and mound formation. Some of the mounds display an apical pit (Fig. 12B), and some shallow sub-circular pits are present also at the base or along the flanks of mounds. Pondrelli et al. (2011a) calculated that within the HiRISE image PSP_003788_1820, $\sim 35 \%$ of the mounds possess an apical pit, and further argued that the orifices represent depositional morphologies within the mounds. The fact that more than one-third of the mounds possess a depression exactly at their top makes an impact origin improbable. In addition, the depressions are much smaller than the mounds themselves (1\%-2\% size ratio) (Pondrelli et al., 2011a), rendering unlikely the armoring of surrounding 


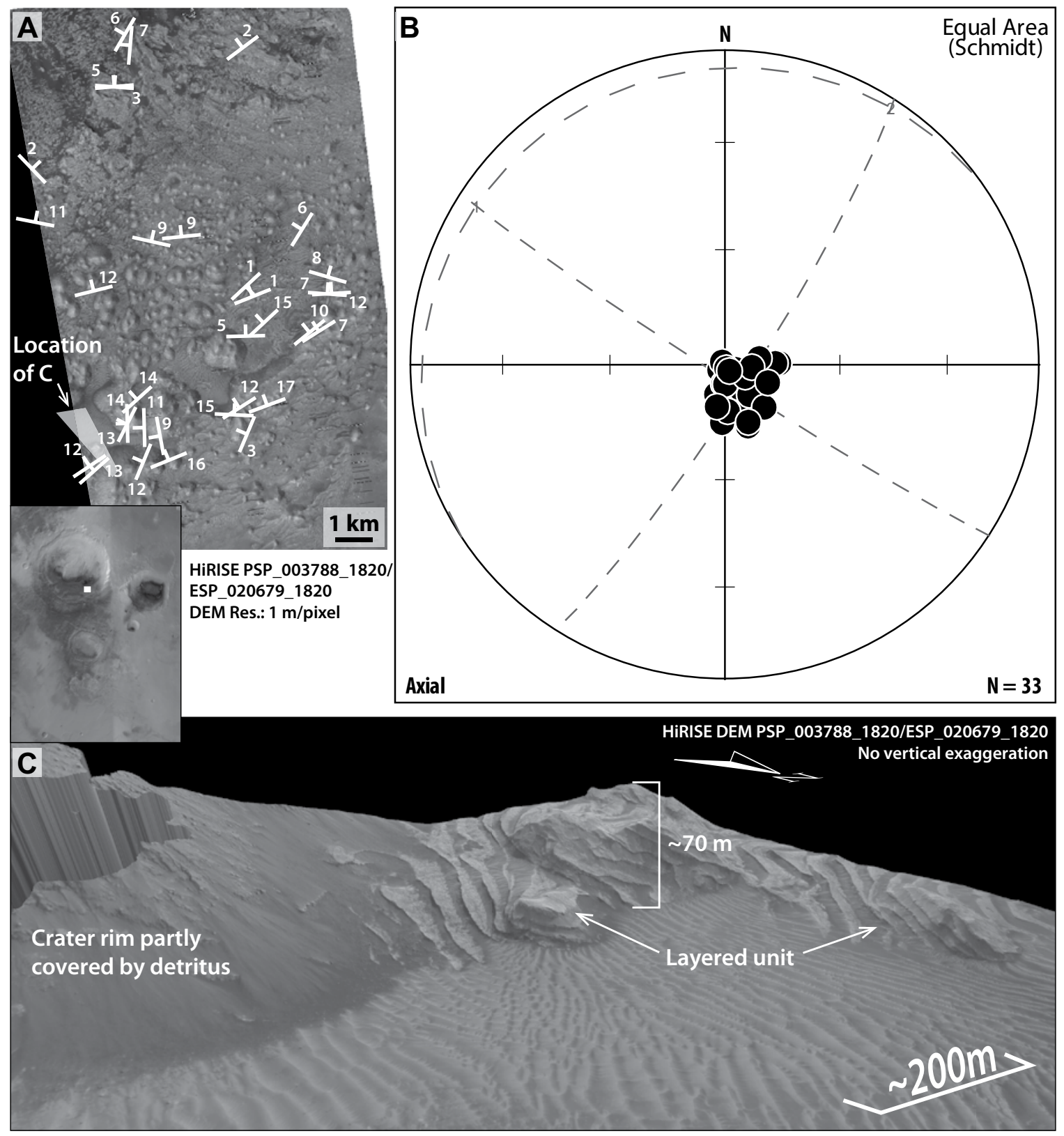

Figure 9. Layer attitude in the layered unit of the equatorial layered deposits (ELDs) located in the southeastern part of Firsoff crater. (A) HiRISE-based map with the measured layer attitudes. See Figure DR1 (see footnote 1) for details. The location of the image is indicated in the HRSC mosaic shown in the lower left inset. The white transparent box in the lower left of the image represents the location of $C$. (B) Stereonet representing attitude values. The diagram shows a tight cluster but a definite preferred orientation. (C) Layered unit material draping crater rim deposits. Note the absence of cross-stratification at the scale of the available resolution. The artifact present in the left of the image is located outside of the measurement area. See A for location.

substrate by impact craters to form the mounds as erosional remnants. However, the preservation of such features through geologic time appears unlikely. We speculate that the hummocky material might have draped these morphologies thus protecting them from erosion until a more recent exhumation. The association of morphologies and texture is possibly suggestive of a forma- tion related to fluid and/or gas expulsion. It is also possible that some mounds may be erosional remnants of layered deposits, produced by aeolian erosion, in which case the extent of the mound-covered area in the geological map is overestimated (Fig. 2). However, erosional remnants resulting from aeolian processes show morphologies generally elongated along the wind direction, whereas the mounds display a sub-circular outline in plan view (Pondrelli et al., 2011a). Furthermore, the layered unit contains layers disrupted in a polygonal pattern whereas the mounds commonly, although not exclusively, have a brecciated texture. These features are distinguishable at HiRISE scale and make misidentification unlikely. 


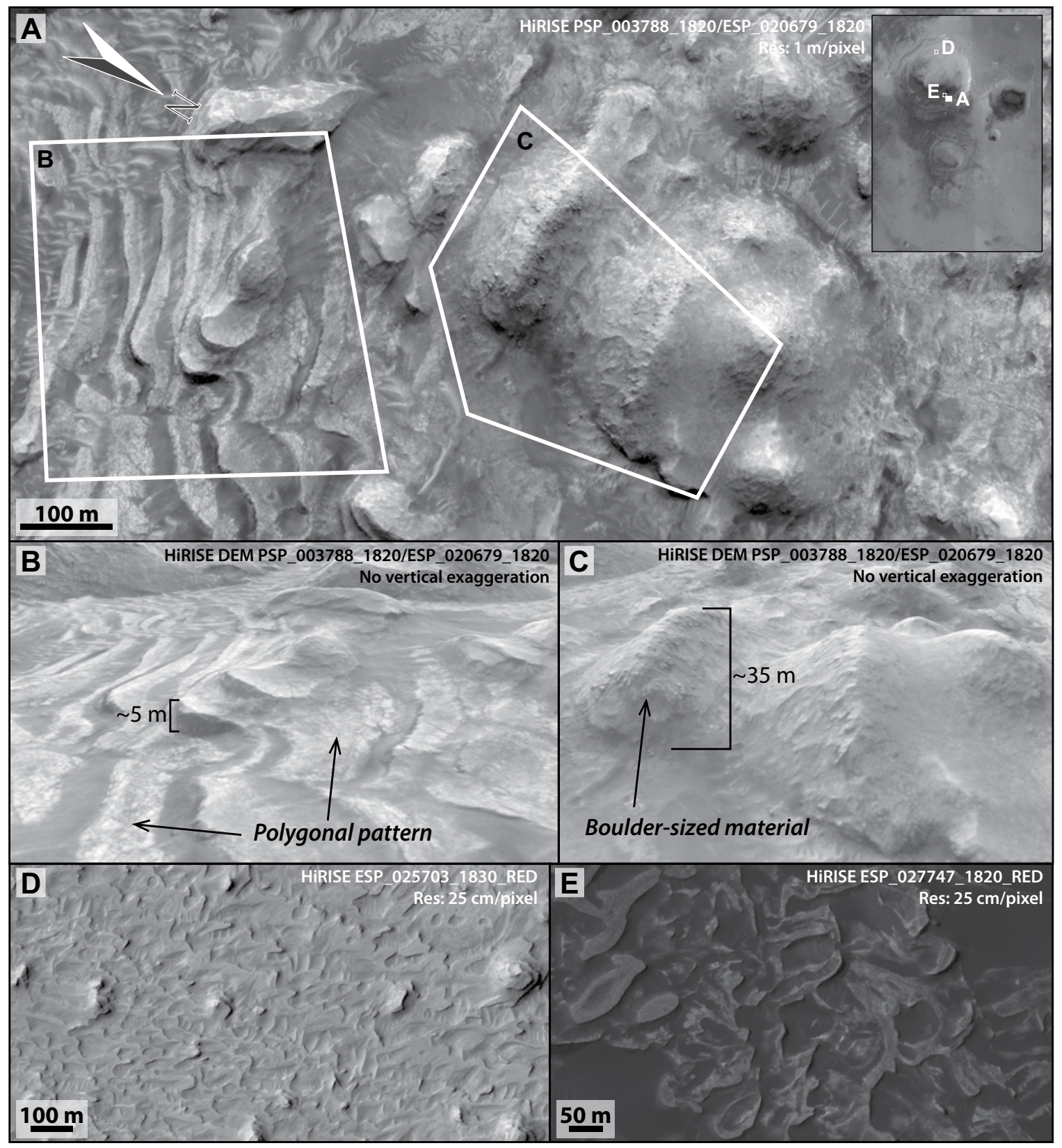

Figure 10. Units of the equatorial layered deposits (ELDs). (A) HiRISE image showing the two units which make the ELDs: layered high-albedo deposits disrupted in a polygonal pattern, and mounds made of boulder-sized mixed with finer-grained material. The two white polygons represent the approximate location of B and C. (B) Example of the layered unit. (C) Example of mounds. (D) Layered unit showing layer morphologies. (E) Depressions, raised rims, and layer morphologies. The location of each image is indicated in the HRSC mosaic at the top right of the figure.

Mounds are everywhere associated with the layered unit (Figs. 12A, 12B), but unambiguous stratigraphic relations are difficult to establish. In some cases, mounds are on top of the layered unit (e.g., Fig. 12B) (Pondrelli et al., 2011a). Locally, layers appear to be up-warped at the flank of the mounds (Fig. 13B), which may suggest either a lateral transition between coeval units or post-depositional bending related to mound formation. The mound imaged in Figure $13 \mathrm{C}$ shows a well-bedded mound $\sim 250 \mathrm{~m}$ in diameter and $120 \mathrm{~m}$ in height, with exceptionally well-exposed internal geometries. Layers appear to continue, with some irregularities, from the mounds to the embedding layered unit. This observation suggests a possible facies heteropy, i.e., lateral transition, which in turn implies temporal and genetic association between the two units.

ELDs within Firsoff and in the unnamed crater located immediately east of Firsoff contain hydrated phases (Fig. 14). CRISM spectra display a large shoulder between 2.3 and $2.4 \mu \mathrm{m}$, a large absorption band at $\sim 1.9 \mu \mathrm{m}$, 


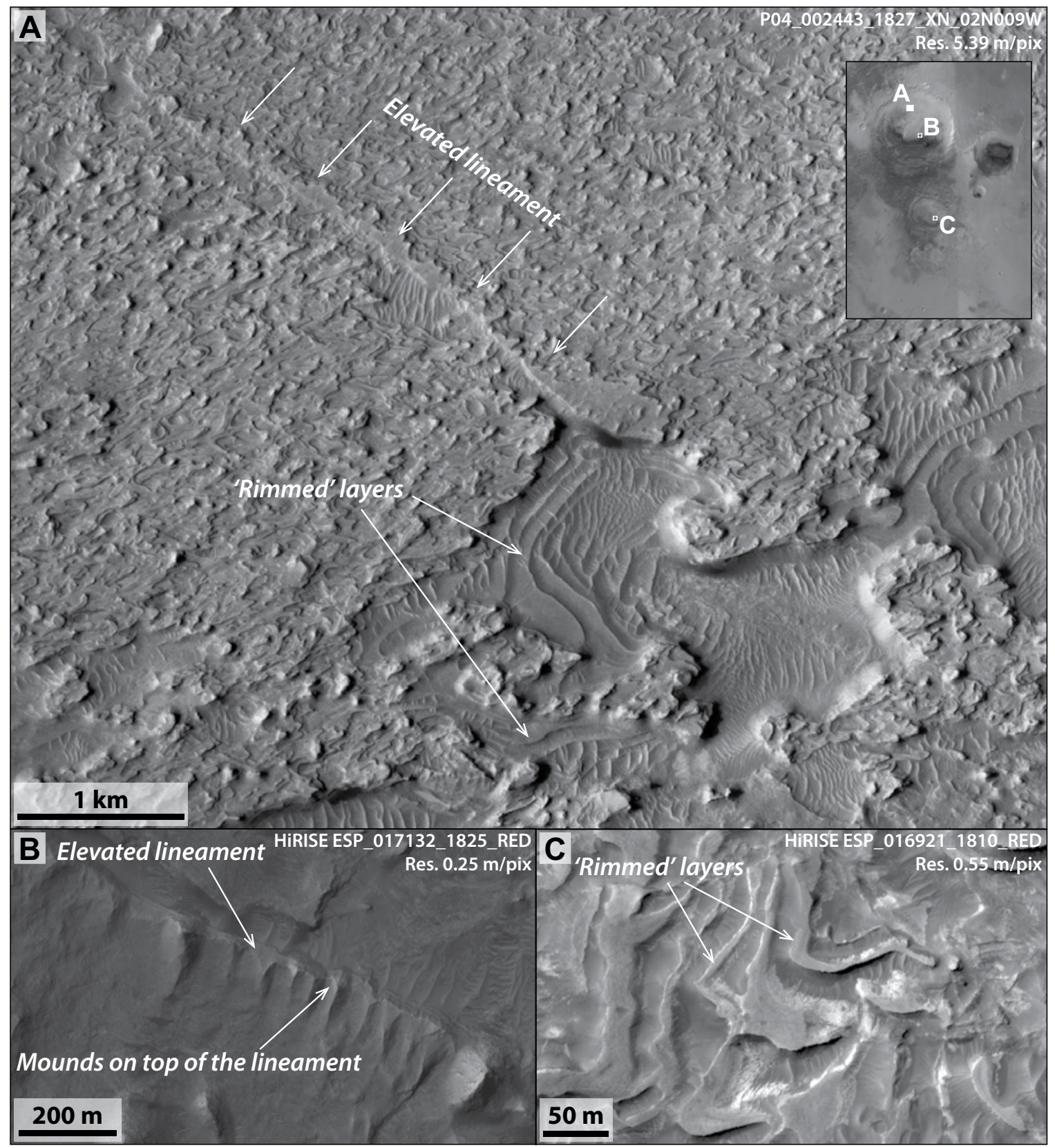

Figure 11. Morphologies of the equatorial layered deposits (ELDs). (A) CTX image showing an example of an elevated lineament (possible fissure ridge). Material appears to source from the subsurface in correspondence with a tectonically controlled fracture. ELD layers appear to be bounded by a rim. (B) Example of an elevated lineament (possible fissure ridge) with mounds developing on the top. (C) Example of ELD layers that seem to be bounded by a rim. The location of the images is indicated in the HRSC mosaic at the top right of the figure.

and a faintly visible band at $\sim 1.4 \mu \mathrm{m}$ (Fig. 14B). These characteristics are due to bound water (Clark et al., 1990) and may be attributed to polyhydrated sulfate and zeolite spectra. As previously mentioned in Carter et al. (2013), distinction between those two mineral groups is not trivial using remote NIR (nearinfrared) spectroscopy. However, zeolites have been detected only in fines in Meridiani
Planum by the Miniature Thermal Emission Spectrometer (Mini-TES) instrument on board the NASA Mars Exploration Rover Opportunity (Glotch et al., 2006). Because ELDs in our study area likely correspond to similar formations as those in Meridiani Planum, we infer that the hydrated minerals detected in our study area correspond to polyhydrated sulfates rather than zeolites.

\section{ELDS ON THE PLATEAU}

ELDs on the plateau share some of the basic textural and albedo characteristics of ELDs within craters: they are high-albedo, layered deposits disrupted in a polygonal pattern (Fig. 15A). These characteristics led us to group these deposits with the ELDs (Le Deit et al., 2010). 


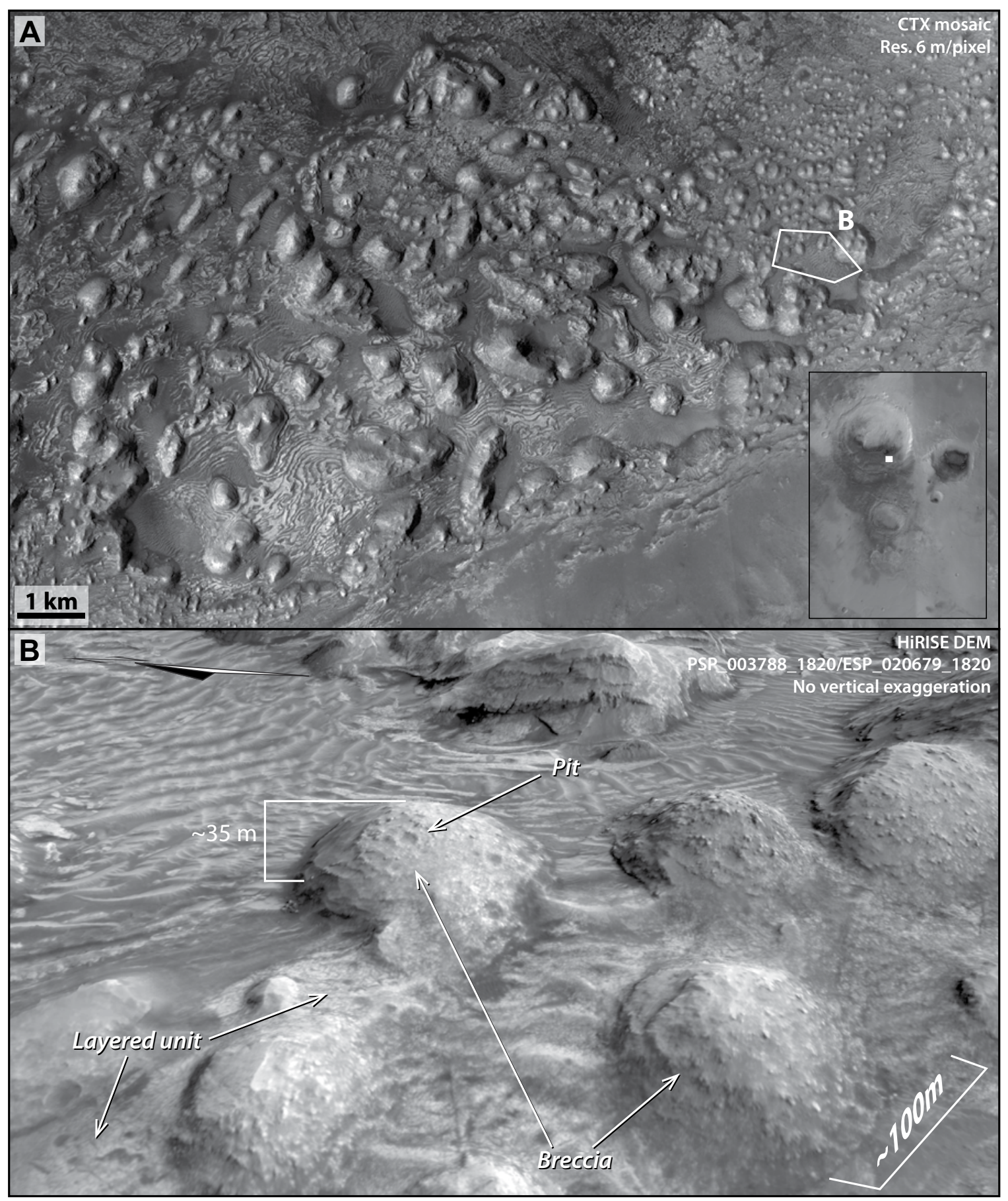

Figure 12. Mounds. (A) Field of simple and complex mounds in the southern part of Firsoff crater (see inset for location). Location of $B$ is shown by the white-bounded polygon. (B) HiRISE-derived three-dimensional view of simple mounds.

Still, other elements allow us to distinguish the ELDs in the craters from those on the plateau. Such elements include their geometry as depositional bodies (Fig. 7), and some textures and morphologies that can be identified at HiRISE scale. In particular, ELDs on the plateau consist of mounds, flat-lying bedded to faintly bedded deposits, and bedded deposits forming dune fields.

Mounds, although widespread on the plateau, are generally poorly exposed due to dust coverage or erosion. It is not possible to clearly observe their texture and exclude that they represent erosional remnants produced by post-depositional aeolian erosion of previously deposited ELDs. Still, their scale and shape are similar to those of the mounds in the craters, and in places they seem to possess an apical pit. This suggests that at least some of them might represent the equivalent of the features observed in the craters (Pozzobon et al., 2013). 


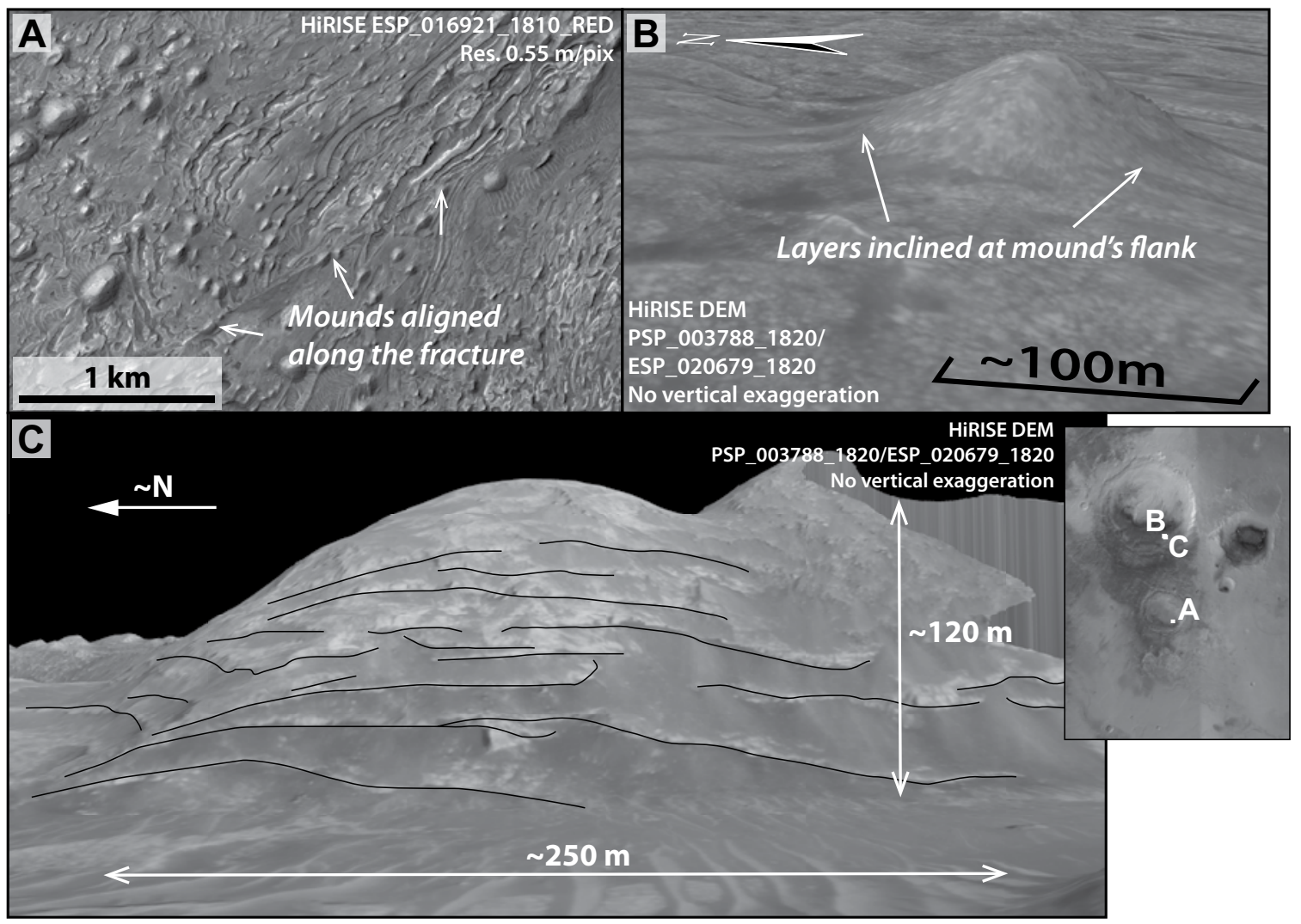

Figure 13. (A) Example of mounds aligned along fractures and not (redrawn after Franchi et al., 2014). (B) Layers up-warped at the flanks of the mounds. (C) Depositional geometry of a mound and relation with the layered unit. Layers continue from the mounds to the layered unit, suggesting facies heteropy between the units. The artifact present in the right part of the image does not affect the mound geometry. The location of the images is indicated in the HRSC mosaic shown in the lower right corner of the figure.

Flat-lying bedded to faintly bedded deposits are characteristic of an approximately horizontal flat unit (Fig. 15A), which shows rectilinear troughs and ridges sculpted by differential aeolian erosion possibly emphasizing pre-existing more resistant features (Edgett and Malin, 2002). ELDs are disrupted in a polygonal pattern and in places show smaller-scale ridges (probably not more than tens of meters in height according to CTX-based DEMs) which resemble eroded dune crests (Fig. 15B). Disconformities are locally visible; in places they separate levels with ridges and levels made up of planar beds (Fig. 15B).

The bedded deposits forming dune fields represent the best-exposed ELDs unit on the plateau (Fig. 15C). The dunes are present at different scales, although erosion as well as later depositional cover complicate a detailed reconstruction of their morphologies and stratigraphy, and make it difficult to infer regional flow direction(s). However, erosional windows locally display the presence of cross-stratification (Figs. 15C, 15D). Some metric to decametric thick cross-beds are irregular, suggesting the presence of flows of different directions and partial reworking of previously deposited beds. To illustrate the similarity to a terrestrial analogue, Figure $15 \mathrm{E}$ is a satellite view (i.e., the same viewpoint and comparable scale of Mars images) of cross-stratification in the Early Jurassic Navajo Sandstone (southern Utah, USA).

The scale of the cross-stratification and the lack of association with water-related landforms such as fluvial channels suggest a formation in an aeolian depositional environment.

ELDs on the plateau possibly contain hydrated minerals (i.e., sulfates, phyllosilicates). The occurrence of barely visible signatures of hydrated minerals in two CRISM observations do not ensure their hydrated minerals detection from orbit (Fig. 14A).

\section{DISCUSSION}

The stratigraphic position of ELDs can be constrained between the cratered unit and the subdued crater unit of the plateau sequence at their base, and between the hummocky mate- rial and the ridged plains material at their top (Fig. 3B). Crater count data constrain this to the Noachian-Hesperian transition and the lower part of the early Amazonian (Figs. 6A, 6B).

ELDs were found to contain polyhydrated sulfates in three CRISM observations in Firsoff crater and in the crater east of Firsoff (Fig. 14). Because of the similarity of these ELDs with those located elsewhere in the study area, we suggest that most if not all ELDs might represent polyhydrated sulfate-bearing deposits. Sulfate-bearing high-albedo layered deposits present elsewhere on Mars have been interpreted to span the age range from the Noachian-Hesperian transition into the early Hesperian (e.g., Gendrin et al., 2005; Bibring et al., 2006; Le Deit et al., 2008; Poulet et al., 2008), and these share the same basic morphologic and spectral characteristics of the ELDs in the study area. Layer morphologies, albedo, structure, composition, and stratigraphic setting enable us to include the ELDs in Firsoff crater and the surrounding plateau in the wider frame of the sulfate-bearing layered deposits seen elsewhere on Mars. 
Figure 14. Sulfate-rich deposits in the study area. (A) Subset of HRSC nadir mosaic overlain by CRISM footprints of observations showing sulfates in craters. Observations on plateaus possibly indicate hydrated minerals. (B) CRISM ratioed spectra compared to laboratory spectra of zeolites and polyhydrated sulfates (RELAB library spectra [NASA Reflectance Experiment Laboratory, http://www .planetary.brown.edu/relabdocs /relab.htm]). I/F-measured radiance divided by solar irradiance. The ratioed spectrum of the CRISM observation FRT C384 corresponds to an average of 30 pixels divided by an average of 35 pixels of a neutral region; for observation FRT $236 \mathrm{DE}$, it corresponds to an average of 32 pixels divided by 25 pixels, and for observation FRT 2437E, and average of 4677 by 356. (C) False-color image of the CRISM observation FRT C384. IR-infrared. (D) Spectral parameter map of the same observation (red, SINDEX; blue, BD1900R). Displayed values: red, 0.037-0.054; blue, 0.014-0.024. Pink tones indicate occurrence of polyhydrated sulfates, and blue tones of hydrated phases. (E) False-color image of the CRISM observation FRT 236DE. (F) Spectral parameter map of the same observation (BD1900R). Displayed values: 0.002-0.010. White tones indicate occurrence of hydrated phases. (G) False-color image of the CRISM observation FRT 2437E. (H) Spectral parameter map of the same observation (BD1900R). Displayed values: 0.003-0.010. White tones indicate occurrence of hydrated phases.
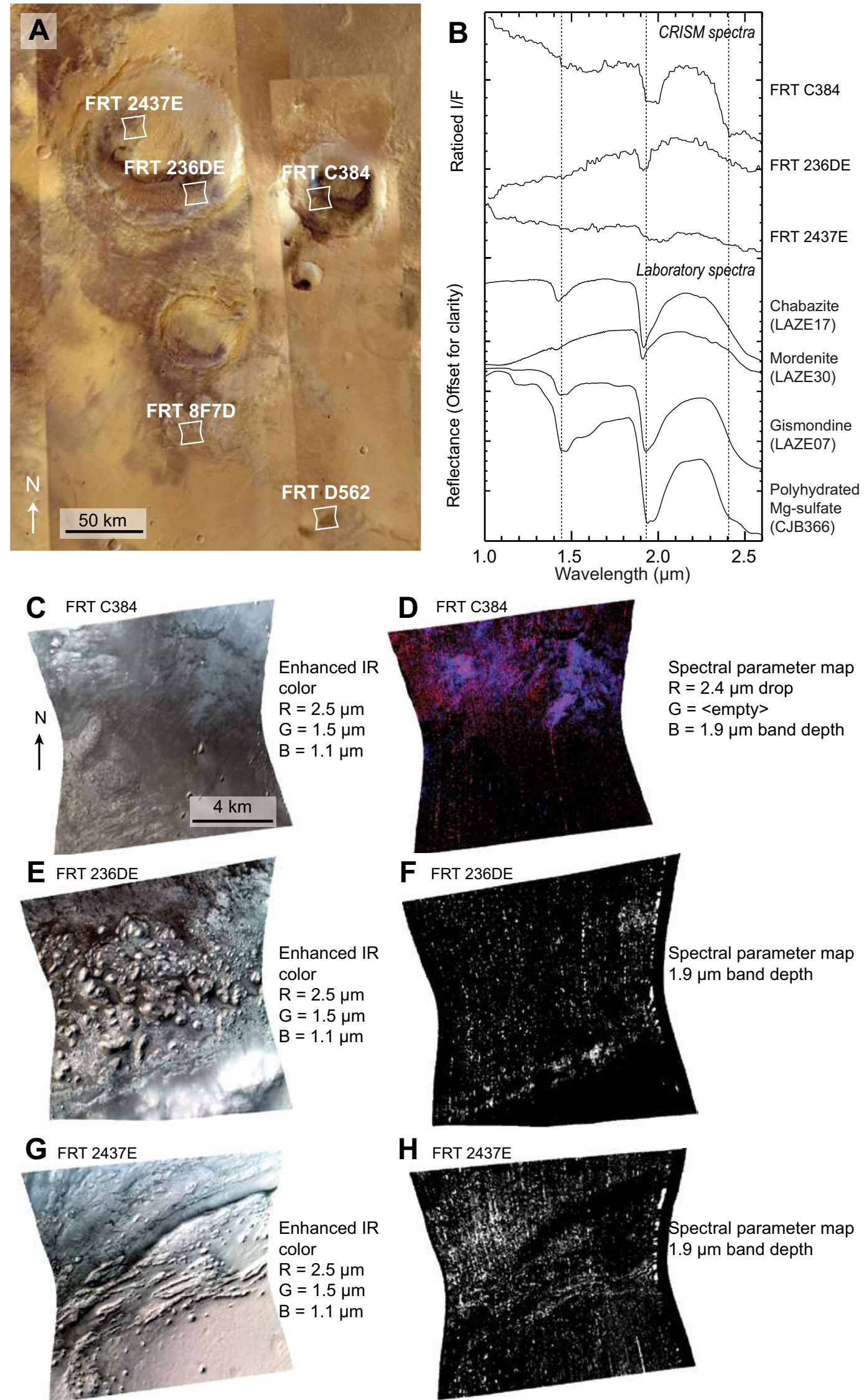

H FRT 2437E

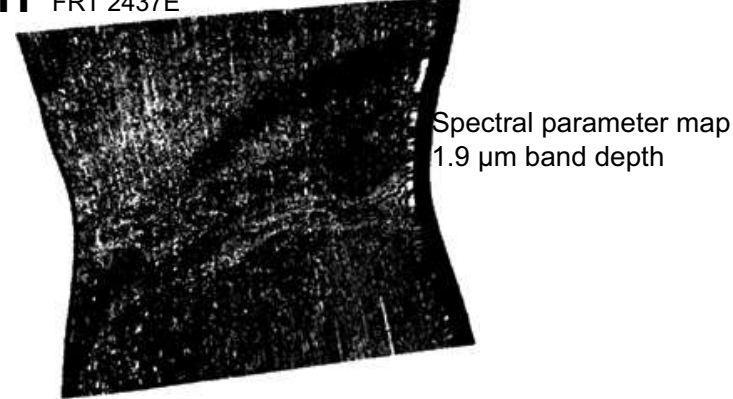




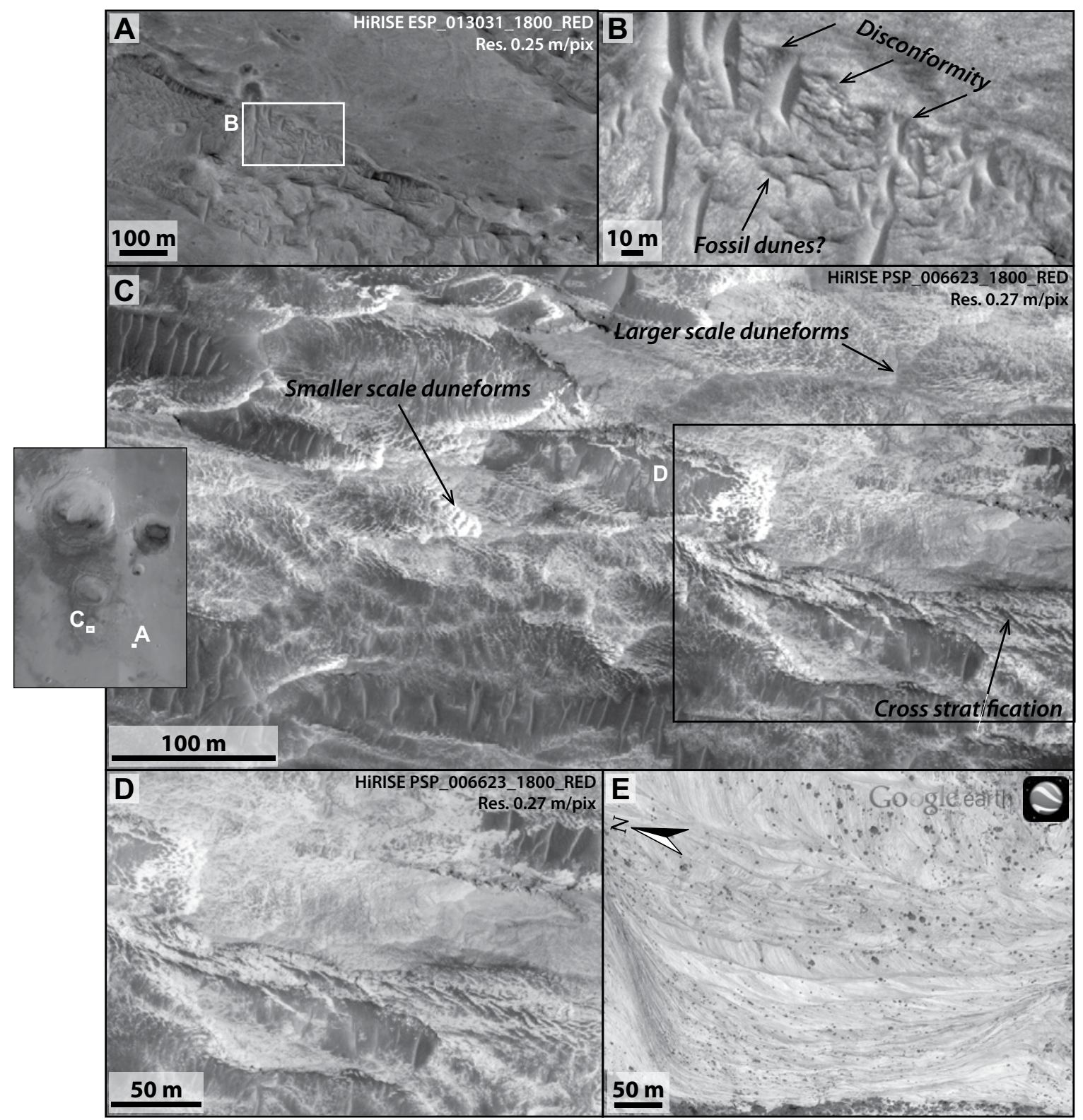

Figure 15. Example of equatorial layered deposits (ELDs) on the plateau. The location of the images is indicated in the HRSC mosaic at the left of the figure. (A) Flat-lying bedded to faintly bedded deposits. The boxed area represents the location of B. (B) ELDs on the plateau are characterized by high albedo and are disrupted in polygonal pattern as in the craters. Possible dune deposits are covered in disconformity by flat-lying bedded deposits. (C) Bedded deposits associated with dune fields. The boxed area represents the location of D. (D) Meter-scale cross-stratification (see text for discussion). (E) Example of meter-scale cross-stratification from the Early Jurassic Navajo Sandstone (southern Utah, USA). Google Earth image (centered on $\left.37^{\circ} 11^{\prime} 22.81^{\prime \prime} \mathrm{N}, 112^{\circ} 57^{\prime} 16.73^{\prime \prime} \mathrm{W}\right)$, used with permission.

ELDs found in craters and in the plateau (Fig. 2) can be distinguished from each other on the basis of basin-scale morphologies (kilometers-thick crater bulges versus hundreds-of-meters-thick sheet drape deposits) and local-scale morphologies (rounded shape, sub-circular depressions, raised rims, bowl-shaped appearance, and serrated layers versus flat-topped bodies or dune fields with cross-stratification). These morphologic differences suggest that genetic processes might at least partly be different, too.

Aeolian erosion was one of the main processes that shaped the morphology of the ELDs' architecture inside and outside craters. This demonstrates that ELDs are easily erodible by wind (Figs. 2, 8A, 8D). Still, most of the morphologies within craters do not show the typical characteristics (yardangs, preferential elongation, differential erosion) associated with wind erosion. These morphologies are mostly concentrated in the topmost part of the Firsoff crater bulge.

Most ELDs display rounded shapes, subcircular depressions, raised rims, bowl-shaped appearance, and serrated layers (Figs. 8B, 8C, 
$8 \mathrm{D}, 10 \mathrm{D}, 10 \mathrm{E})$. These morphologies are consistent with syn- to post-depositional chemical etching processes leading to partial solution (Murana and Kneissl, 2014), but may also result from locally different depositional rates resulting in changes in layer thickness. These characteristics appear to be consistent with a depositional or water-related weathering origin rather than with an aeolian erosional product.

A depositional origin of a crater bulge has been proposed also by Kite et al. (2013a) and Le Deit et al. (2013) in Gale crater, while according to most authors (e.g., Malin and Edgett, 2000; Andrews-Hanna et al., 2010; Michalski and Niles, 2012), the craters were originally filled with sediments, and only after post-depositional aeolian erosion, bulges in their current form were shaped as erosional remnants. Our data are consistent with the interpretation of Kite et al. (2013a) and Le Deit et al. (2013), but we are cautious not to extend automatically our inferences over the whole range of crater bulges. Although a common origin appears likely, solid evidence based on geological observations must be sought and evaluated separately in each locale before reaching regional interpretations and models.

The presence of polyhydrated sulfates within the rock component has been associated and is potentially consistent with a formation through evaporitic processes (e.g., Grotzinger et al., 2005) either as cement or main constituent. The polygonal pattern that extensively disrupts the ELDs inside and outside craters (Fig. 10B) might reflect desiccation cracks in evaporites (e.g., Grotzinger et al., 2005), possibly occurring during later diagenesis in the phreatic zone or capillary fringe of a groundwater table (McLennan et al., 2005). Polygonal patterns of comparable scale have been alternatively suggested to form as a consequence of post-depositional weathering, although still in the presence of salts (Chan et al., 2008).

Morphologies such as the rounded shapes, the sinuous margins, and the quasi-circular depressions are typical of, although not exclusive to, evaporite deposits (e.g., Bruthans et al., 2009). On Earth such landforms develop by dissolution processes thus implying the presence of water, which in turn implies that such erosion occurred at the time of deposition or before the establishment of dry conditions. Bowl-shaped features and raised rims might represent erosional products of originally more uniform layers or result from laterally inhomogeneous deposition rates.

Although no single observation can point exclusively to an evaporite composition of the ELDs located in the craters, all data are consistent with this interpretation.

Putative fissure ridges and mounds may be indicative of fluid expulsion, thus suggesting that the source area of the ELDs was in the subsurface (Figs. 8D, 11A, 11B, 12A, 12B, $13 \mathrm{~A}, 13 \mathrm{~B}, 13 \mathrm{C})$. Although fissure ridges may have originated on faults and/or fractures as suggested by their generally straight shape, no evidence of offset has been found. Moreover, they are wedge shaped (Fig. 11A), which suggests either a higher deposition rate or a better cementation than the ELDs distant from the fissure ridges, and are frequently associated with mounds developing at their top (Figs. 8D, 11B). These prominent morphologies suggest fluid expulsion of sulfate-rich fluids which precipitate evaporites after their expulsion.

Mounds consist of layered to non-layered breccia mixed with a finer-grained matrix (Pondrelli et al., 2011a) or, more rarely, of layered deposits (Figs. 10C, 12B). Even if some mounds are the erosional remnants of the layered unit produced by aeolian activity, their generally different texture (observed at HiRISE scale) and the common presence of an apical pit (Fig. 12B) point toward a depositional origin for at least a part of the mounds (see discussion in Pondrelli et al., 2011a). The lateral gradual transition between the layered unit and the mounds (Fig. 13C) suggests that these units are coeval, and thus reflect adjacent depositional environments. Like the fissure ridges of the layered units, the pits on the mounds are suggestive of fluid expulsion processes (Pondrelli et al., 2011a). Layers in some places deepen where they pass laterally at the flanks of some mounds (Figs. 13B, 13C), which is consistent with a lateral gradual transition between layers and mounds.

The available image resolution does not permit discernment of whether the boulders forming the mounds actually represent clastic or crystalline materials. Hence, the term breccia is used simply to describe the unit. This distinc- tion is entirely descriptive because it implies a different genetic mechanism. Fluid expulsion can lead to the formation of mounds such as the ones observed in the study area, in fact, either by mud volcanism (Pondrelli et al., 2011a), a clastic process, or spring precipitation, a chemical process. The lateral transition between the mounds and the layered unit is a transition between the mounds and a unit characterized by the presence of fissure ridges. Both morphologies are suggestive of an evaporitic composition, possibly with polyhydrated sulfates as components. This appears to be consistent with a spring deposit formation, whereas the mud volcanism process seems less likely. Under such spring deposits, the boulders found in the mounds would represent crystallized masses and/or better-cemented blocks broken after cementation by the upwelling fluid and transported toward the surface. Thus, the use of the terms clasts or breccia is not entirely inappropriate.

On the basis of the evidence at all scales, we suggest a spring deposit scenario for the ELDs deposited in the craters (Fig. 16). The bulge morphology (Fig. 7B) might have resulted from chemical precipitation following water upwelling similar in process, though not in composition, to the terrestrial vent systems. Fluid upwelling and expulsion might have been favored by pre-existing fractures formed during crater formation (Pondrelli et al., 2011a). Fissure ridges and mounds would represent the pathways that would have allowed the actual expulsion (Figs. $8 \mathrm{D}, 11 \mathrm{~A}, 11 \mathrm{~B}, 12 \mathrm{~A}, 12 \mathrm{~B}, 13 \mathrm{~A}, 13 \mathrm{~B})$. The polyhydrated sulfates detected among the components (Fig. 14), the presence of the polygonal pattern (Fig. 10B), as well as morphologies such as the rounded shapes, the sub-circular depressions, and the serrated pattern (Figs. 8B, 8C, $10 \mathrm{D}, 10 \mathrm{E})$ are consistent with such a scenario.

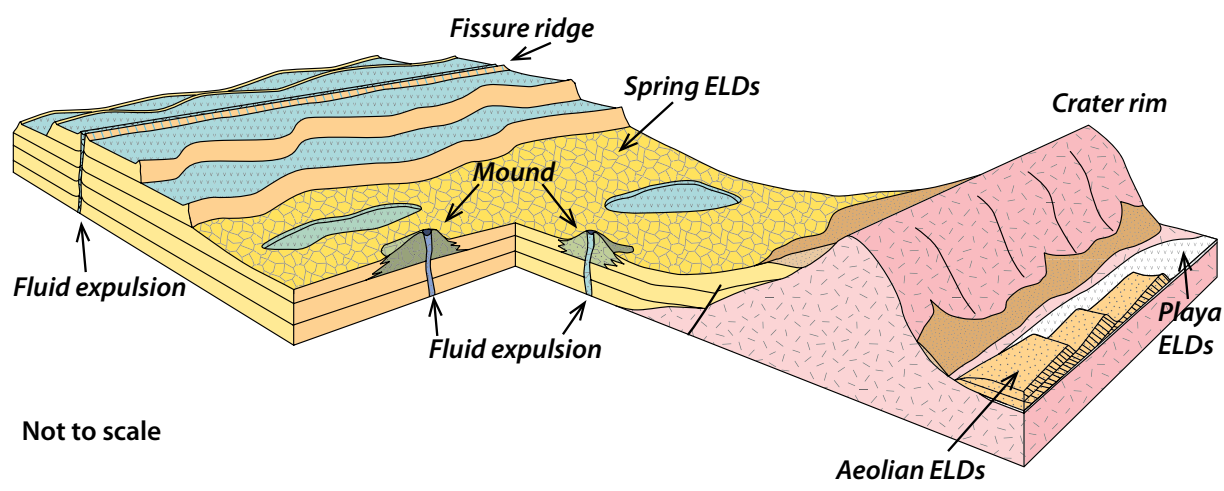

Figure 16. Processes inferred to have caused formation of equatorial layered deposits (ELDs). ELDs inside craters (in yellow) are interpreted as formed by fluid expulsion and spring deposit precipitation. In blue, areas possibly submerged by water are indicated. ELDs outside craters were probably subjected in part to aeolian reworking (light brown) and in part to playa deposition (white). 
The polygonal pattern might have resulted from syn- to post-depositional desiccation while the rounded shapes, the sub-circular depressions, and the serrated pattern may be the result of syn- to post-depositional dissolution. The raised rims, locally associated with bowl-shaped depressions (Figs. 11A, 11C), may be the equivalent of the pool-and-dam (terrace) system typical of terrestrial continental spring systems and the "ridge-and-trough" observed in the nearby Crommelin crater (Franchi et al., 2014). The geometry of the layers, which drape and onlap the older deposits, is also consistent with a formation by evaporite precipitation in probably mixed ephemeral lake and subaerial conditions.

Such a scenario is challenged by different interpretations proposed in other similar crater bulges. According to Kite et al. (2013b) on the basis of models developed for Gale crater, the crater bulge morphology might be explained by airfall deposition because slope winds are expected to peak on the steep crater wall and mound slopes, thus preventing sediments from settling in these zones. However, airfall dust deposition in Firsoff and adjacent craters, even if it can explain the different depositional geometries within the craters and between craters and plateau, would not explain the extensive presence of fluid expulsion features such as fissure ridges and mounds. Moreover, a formation of ELDs by airfall dust deposition would imply the same depositional process in the craters and in the plateau. But on the plateau we documented the differences in morphologies and sedimentary structures such as cross-bedded deposits (Figs. 15C, 15D), which imply a granulometric range (medium sands to granules) inconsistent with airfall settling. Aeolian deposition might have occurred with a variety of processes including settling of fine-grained materials and turbulent transport of coarser-grained (sands to granules) deposits. Still, no cross-bedding was found inside the craters despite the extensive HiRISE coverage. Settling of fine-grained materials later cemented by upwelling groundwater flows might instead explain the observed morphologies, and it cannot be excluded that such processes contributed to the Firsoff stratigraphic column. However, cementation by groundwater fluctuations, associated with the following aeolian reworking of loose sediments, produces sharp flat-lying unconformable surfaces (Stokes surface) (Stokes, 1968; Fryberger et al., 1988) that should be visible at HiRISE scale, at least in correspondence with cross-bedded dune deposits, but that have not been detected. Hence we think it unlikely that aeolian deposition and reworking can explain the observed complexity.

Some authors have proposed that ELD deposition might have been driven by pyroclastic processes (Scott and Tanaka, 1982; Hynek et al., 2003; Kerber et al., 2012; Michalski and Bleacher, 2013). Pyroclastic processes are characterized by deposition in an upper flow regime where antidunes develop, while the dunes on the plateau are typical of lower flow regime. Distal pyroclastic deposits instead would have originated by settling of fine-grained material, not suitable to be reworked in dunes. Moreover, pyroclastic processes alone cannot explain the different character of ELDs between craters and plateau and also cannot explain the presence of the proposed fluid-expulsion features. However, we cannot exclude that some pyroclastic deposits contributed to the geological history of the area.

Kite et al. (2013a) focused their observation on the Gale crater bulge where they described a depositional geometry similar to what we observed in Firsoff crater. They described uniform outward-dipping layers and the absence of clear identifiable unconformities. These authors suggested that such geometry might be inconsistent with a formation by spring deposits because such deposits are typically fed from different spring sources and are precipitated soon after the fluid emergence, and hence tend to form lenticular coalescent bodies rather than uniform dipping strata (Kite et al., 2013a). In our study area, the lateral transition between layers and mounds indicates a more complex scenario. The lateral extension of layers and the continuity of spring deposits depend on water chemistry, temperature, and flow discharge. Low-energy environments might favor the formation of layers with a sub-horizontal attitude (De Filippis et al., 2013). This geometry would contribute to conceal eventual unconformities, especially if the limits of image resolution, the observed disruption by the polygonal pattern, and the dust coverage are considered. In addition, layers formed during even short-lived lacustrine stages may exhibit extensive lateral continuity.

Pitted cones similar to the mounds observed in our study area can form as pingos in periglacial environments, as hypothesized for several locations on Mars (e.g., Balme and Gallagher, 2009; Burr et al., 2009). The presence of a polygonal pattern has a potential analogy with thermal contraction cracks in periglacial environments as well. Ice-related weathering has been shown to explain sulfur formation (e.g., Szynkiewicz et al., 2013).

The mounds in the study area lack the fracture patterns typical of pingos (Müller, 1959; Gurney, 1998; French, 2007; Burr et al., 2009). Most importantly, other possible periglacial morphologies such as scarps with cuspate niches and associated debris apron or "swiss cheese terrain" (MacClune et al., 2003) were not observed.
ELDs on the plateau are associated with dune fields, here interpreted as the result of aeolian deposition. We further suggest that the flat-lying deposits formed as playa deposits during stages of a rising groundwater table (Fig. 16). Mounds may be small spring deposits, possibly formed where water upwelling was favored by the presence of pre-existing fracture systems in the basement (Rossi et al., 2009). A rising groundwater table might also have caused cementation of the aeolian dunes, thus preserving them from aeolian erosion. Groundwater protects the material below the water table from erosion. Material above the water table is preferentially eroded, thus defining the horizontal Stokes surface (Stokes, 1968; Fryberger et al., 1988). Such a depositional geometry might be consistent with the observed flat-lying, horizontal surface between cross-stratified sets in the plateau, but more extensive data are necessary to test this hypothesis.

The overall geological setting in the plateau appears to be very similar to the one depicted in Meridiani Planum (e.g., Grotzinger et al., 2005), with alternating playa and aeolian deposits. The critical role of groundwater in controlling sedimentation and the preservation of sedimentary deposits has been proposed by, e.g., Grotzinger et al. (2005).

We suggest that the groundwater presence and its fluctuations might have been the main control on the geological evolution of the study area (Fig. 17). The importance of groundwater to the formation of ELDs in Arabia Terra has been modeled by Andrews-Hanna et al. (2007, 2010) and Andrews-Hanna and Lewis (2011). Based on different data it has also been supported, to different extents, by others (e.g., Rossi et al., 2008; Pondrelli et al., 2011a; Zabrusky et al., 2012; Franchi et al., 2014). Others have challenged the existence of groundwater (e.g., Michalski and Niles, 2012; Michalski et al., 2013b) or suggested that it is of limited importance (Michalski et al., 2013a). According to these authors, the existence of groundwater would require amounts of sulfur too high and high erosion rates (Michalski and Niles, 2012). In Mawrth Vallis the stratigraphic position of sulfur- and clay-bearing deposits is more consistent with an origin of atmospheric leaching rather than due to groundwater activity (Michalski et al., 2013b). According to Michalski et al. (2013b), the formation of the Mawrth Vallis and possibly similar nearby layered deposits might have been caused by ice and/or snowmediated weathering.

Our observations do not support an extension of such a scenario in the study area. We suggest that the bulge is largely a depositional and not an erosional geometry, so we do not expect particularly high erosion rates. Although hampered 


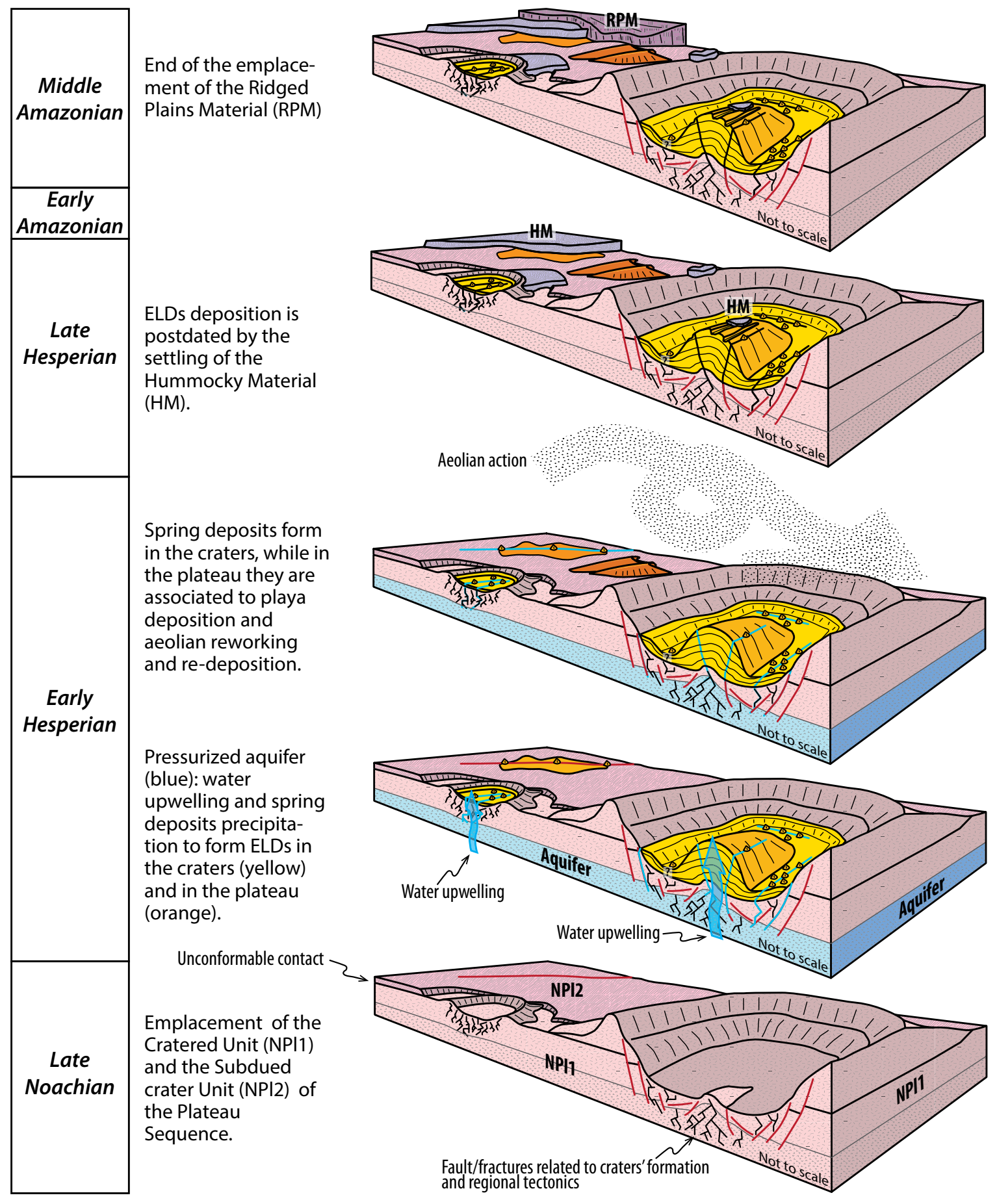

Figure 17. Interpretative scenario of the evolution of the study area through time. From bottom to top, the evolution from the late Noachian to the middle Amazonian is sketched. See text for explanation. ELDs-equatorial layered deposits.

by the paucity of compositional data, we find no evidence for different characteristics in the stratigraphy of ELDs that would suggest differences in mineral composition within the unit.

We observe a widespread distribution of fissure ridges and mounds suggestive of fluid expulsion, which in turn suggests sourcing from the subsurface, but we found no evidence of glacial and/or periglacial deposits and/or snow-related morphologies. Diffuse fractures commonly represent the way for fluid seepage when associated with mounds (e.g., Cavalazzi et al., 2007, 2012).

Differences in the nature of the Noachian units of the plateau sequence, which have been interpreted as a mixture of lava flows, pyroclastic material, and impact breccia for the cratered unit, and interbedded lava flows and eolian deposits for the subdued crater unit (Scott and Tanaka, 1986), would result in differences in their permeability. These differences would control the geometry and behavior of any 
aquifer and associated fluid flows. As a consequence, the aquifer or aquifers were probably characterized by irregular geometries and differences in their lateral extents. Parnell et al. (2010) performed permeability measurements in impact breccia showing their low permeability which would favor fluid circulation to occur mainly through fracture systems.

Groundwater fluctuations might have controlled playa deposition and the preservation of aeolian dunes in the plateau. Upwelling through the fracture systems might have led to spring deposit precipitation in the craters and locally in the plateau.

The presence of spring and playa deposits implies the presence of a hydrological cycle that drives groundwater upwelling at surface temperatures above freezing. For formation of playas, the temperatures should have been above freezing for long periods of time in order to facilitate precipitation-induced recharge of the aquifers and subsequent evaporation. The climate supporting such a cycle was likely arid by terrestrial standards, and such surface conditions in a mineralogically similar terrestrial environment would have been conducive for microbial colonization (e.g., Dong et al., 2007; Glamoclija et al., 2011, 2012). On Earth, playa environments host taxonomically diverse microbial communities adapted to high salt concentrations and dehydration stress due to exposure to long periods of drought (Ventosa et al., 2008; Hollister et al., 2010; Glamoclija et al., 2011).

Spring deposits and playa deposits are potentially suitable targets when searching for life or traces of life (e.g., Dohm et al., 2011; Barbieri and Cavalazzi, 2014; Walter and Des Marais, 1993; Cady and Farmer, 1996; Glamoclija et al., 2011, 2012). The potential for habitability has been subject of ongoing scientific discussions, and the presence of sulfates (whether associated or not with hydrothermal conditions) has been inferred as an indication of potentially habitable conditions (e.g., Mustard et al., 2008; Wiseman et al., 2010). However, Tosca et al. (2008) used geochemical modeling and estimated that the salinity might not be conducive to life. We cannot with certainty apply Tosca et al.'s (2008) conclusions to the entire region, as the variability of these systems on Mars is unknown without proper ground investigations, however this is something to pay attention to when planning for the next astrobiology space missions. Further, sulfates have been shown to have a good potential to preserve biosignatures (Panieri et al., 2010; Allwood et al., 2013; Benison and Karmanocky, 2014), making these deposits appealing targets for astrobiology and exploration of habitability of the red planet.

\section{CONCLUSIVE REMARKS AND INTERPRETATIVE SCENARIO}

The geological succession of the study area begins with the emplacement of the cratered unit and the subdued crater unit, both part of the plateau sequence (Scott and Tanaka, 1986) (Fig. 17). According to crater count results, these two units would have been emplaced during the late Noachian. ELDs are found to rest nonconformably on top of the plateau sequence. In particular, they lie on top of the cratered unit in the craters and on top of both the cratered and subdued crater units on the plateau. ELDs are themselves unconformably overlain by the hummocky material in the craters as well as on the plateau, and by the ridged plains material on the plateau. Crater count data constrain ELDs deposition between the Noachian-Hesperian transition and the early Amazonian.

We hypothesize that during this interval, a partially confined aquifer entered in contact with the fault and/or fractures related to crater formation as well as with fault and/or fractures possibly related to normal regional faulting. This aquifer led to fluid circulation and upwelling and spring deposit precipitation ("spring ELDs"). The extensive and interconnected fractures associated with craters possibly favored fluid upwelling in the craters, which ultimately resulted in the formation of bulges.

We hypothesize that local fluid upwelling along faults led to mound formation on the plateau. This setting was associated with evaporative pumping and/or possibly ephemeral lake formation leading to playa deposition ("playa ELDs"), although we find no evidence for lacustrine stages within the craters. Aeolian processes (resulting in "aeolian ELDs") were always present, but were likely geologically more significant when the fluid upwelling processes were of lower intensity or simply stopped. During these phases some ELDs might have been deposited by dust airfall or even aeolian dunes. When fluid upwelling processes were active, aeolian processes were probably obscured, leaving no or limited evidence in the geological record.

It is not possible to estimate the duration and the continuity of such evolution based on the data available in this region. On Earth, spring deposits show sedimentation rates ranging from less than a millimeter to several centimeters per year (Anderson and Wells, 2003; Pentecost, 2005), which implies that the spring ELDs might have been emplaced in a geologically short period. Because it is not possible to identify the controls on the deposition of the spring deposits, these parameters cannot be quantified. The absence of extensive unconformities suggests that spring deposit growth was a relatively continuous process. This does not rule out the possibility that other processes, including aeolian airfall or pyroclastic deposition, might have contributed to the observed features.

The study area lacks sufficient exposure to better constrain the presence of a cyclic depositional pattern such as the one documented in Becquerel crater (Lewis et al., 2008). Nevertheless, the change of texture, resistance to weathering, and locally albedo suggests a fluctuation of the relative intensity and/or distribution of the different controls through time. This might have caused different deposition rates even in the context of a continuous process. Fluctuation of the water table, which depends on the climatic conditions, was a potentially important control.

\section{ACKNOWLEDGMENTS}

We are sincerely indebted to Nadine Barlow, Caleb Fasset, and an anonymous reviewer for their constructive and insightful comments that greatly helped us to improve the manuscript. We acknowledge the International Space Science Institute (Bern) that founded the activity of the International Team on "Interior Layered Deposits: What Do They Tell Us about Mars Evolution?" led by T. Zegers and E. Hauber. We thank the HRSC Experiment Teams at DLR Berlin and Freie Universität Berlin as well as the Mars Express Project Teams at ESTEC and ESOC (European Space Research and Technology Centre / European Space Operations Centre) for their successful planning and acquisition of data as well as for making the processed data available to the HRSC Team. We acknowledge the effort of the HRSC Co-Investigator Team members and their associates who have contributed to this investigation in the preparatory phase and in scientific discussions within the team. MP research was funded by the Italian Space Agency (EXOMARS SCIENZA - FASE C2/D) and the Italian Ministry of University and Research. This is ISMAR-CNR, U.O.S.-Bologna, scientific communication number 1856. LLD was supported by the Centre National D'Études Spatiales (CNES). This paper is dedicated to the memory of Gerhard Neukum.

\section{REFERENCES CITED}

Allen, C.C., and Oehler, D.Z., 2008, A case for ancient springs in Arabia Terra, Mars: Astrobiology, v. 8 , p. 1093-1112, doi:10.1089/ast.2008.0239.

Allwood, A.C., Burch, I.W., Rouchy, J.M., and Coleman, M., 2013, Morphological biosignatures in gypsum Diverse formation processes of Messinian ( 6.0 Ma) gypsum stromatolites: Astrobiology, v. 13, p. 870-886, doi:10.1089/ast.2013.1021.

Anderson, J.A., Sides, S.C., Soltesz, D.L., Sucharski, T.L., and Becker, K.J., 2004, Modernization of the Integrated Software for Imagers and Spectrometers, in Proceedings, 35th Lunar and Planetary Science Conference, League City, Texas, 15-19 March 2004: Houston, Lunar and Planetary Institute, abstract 2039.

Anderson, K.C., and Wells, S.G., 2003, Latest Quaternary paleohydrology of Silurian Lake and Salt Spring Basin, Silurian Valley, California, in Enzel, Y., Wells, S.G., and Lancaster, N., eds., Paleoenvironments and Paleohydrology of the Mojave and Southern Great Basin Deserts: Geological Society of America Special Paper 368, p. 129-141, doi:10.1130/0-8137-2368-X.129.

Andrews-Hanna, J.C., and Lewis, K.W., 2011, Early Mars hydrology: 2. Hydrological evolution in the Noachian and Hesperian epochs: Journal of Geophysical Research, v. 116, E02007, doi:10.1029/2010JE003709. 
Andrews-Hanna, J.C., Phillips, R.J., and Zuber, M.T., 2007, Meridiani Planum and the global hydrology of Mars: Nature, v. 446, p. 163-166, doi:10.1038/nature05594.

Andrews-Hanna, J.C., Zuber, M.T., Arvidson, R.E., and Wiseman, S.M., 2010, Early Mars hydrology: Meridiani playa deposits and the sedimentary record of Arabia Terra: Journal of Geophysical Research, v. 115, E06002, doi:10.1029/2009JE003485

Arvidson, R.E., Squyres, S.W., Bell, J.F., III, Catalano, J.G., Clark, B.C., Crumpler, L.S., De Souza, P.A., Jr., Fairén, A.G., Farrand, W.H., Fox, V.K., Gellert, R., Ghosh, A., Golombek, M.P., Grotzinger, J.P., Guinness, E.A., Herkenhoff, K.E., Jolliff, B.L., Knoll, A.H., Li, R., McLennan, S.M., Ming, D.W., Mittlefehldt, D.W., Moore, J.M., Morris, R.V., Murchie, S.L., Parker, T.J., Paulsen, G., Rice, J.W., Ruff, S.W., Smith, M.D., and Wolff, M.J., 2014, Ancient aqueous environments at Endeavour crater, Mars: Science, v. 343, 1248097, doi 10.1126/science. 1248097

Balme, M.R., and Gallagher, C., 2009, An equatorial periglacial landscape on Mars: Earth and Planetary Science Letters, v. 285, p. 1-15, doi:10.1016/j.epsl.2009 .05 .031

Barbieri, R., and Cavalazzi, B., 2014, How do modern extreme hydrothermal environments inform the identification of Martian habitability? The case of the El Tatio geyser field: Challenges, v. 5, p. 430-443, doi: 10.3390 /challe5020430.

Benison, K.C., and Karmanocky, F.J., 2014, Could microorganisms be preserved in Mars gypsum? Insights from terrestrial examples: Geology, v. 42, p. 615-618 doi:10.1130/G35542.1.

Beyer, R.A., Stack, K.M., Griffes, J.L., Milliken, R.E., Herkenhoff, K.E., Byrne, S., Holt, J.W., and Grotz inger, J.P., 2012, An atlas of mars sedimentary rocks as seen by HIRISE, in Grotzinger, J.P., and Milliken, R.E., eds., Sedimentary Geology of Mars, SEPM (Society for Sedimentary Geology) Special Publication 102, p. 49-95.

Bibring, J.-P., Langevin, Y., Gendrin, A., Gondet, B., Poulet, F., Berthé, M., Soufflot, A., Arvidson, R., Mangold, N., and Mustard, J., 2005, Surface diversity as revealed by the OMEGA/Mars Express observations: Science, v. 307, p. 1576-1581, doi:10.1126/science.1108806.

Bibring, J.-P., Langevin, Y., Mustard, J.F., Poulet, F., Arvidson, R., Gendrin, A., Gondet, B., Mangold, N., Pinet, P., Forget, F., Berthe, M., Gomez, C., Jouglet, D. Soufflot, A., Vincendon, M., Combes, M., Drossart, P., Encrenaz, T., Fouchet, T., Merchiorri, R., Bellucci, G., Altieri, F., Formisano, V., Capaccioni, F., Cerroni, P., Coradini, A., Fonti, S., Korablev, O., Kottsov, V., Ignatiev, N., Moroz, V., Titov, D., Zasova, L., Loiseau, D., Pinet, P., Douté, S., Schmitt, B., Sotin, C., Hauber, E., Hoffmann, H., Jaumann, R., Keller, U., Arvidson, R., Duxbury, T., Forget, F., and Neukum, G., 2006 , Global mineralogical and aqueous Mars history derived from OMEGA/Mars express data: Science, v. 312 , p. $400-404$, doi: $10.1126 /$ science. 1122659 .

Bishop, J.L., Parente, M., Weitz, C.M., Noe Dobrea, E.Z. Roach, L.H., Murchie, S.L., McGuire, P.C., McKeown, N.K., Rossi, C.M., Brown, A.J., Calvin, W.M., Milliken, R., and Mustard, J.F., 2009, Mineralogy of Juventae Chasma: Sulfates in the light-toned mounds, mafic minerals in the bedrock, and hydrated silica and hydroxylated ferric sulfate on the plateau: Journal of Geophysical Research, v. 114, E00D09, doi:10.1029 /2009JE003352.

Broxton, M.J., and Edwards, L.J., 2008, The Ames Stereo Pipeline: Automated 3D surface reconstruction from orbital imagery, in Proceedings, 39th Lunar and Planetary Science Conference, League City, Texas, 10-14 March 2008: Houston, Lunar and Planetary Institute, abstract 2419.

Bruthans, J., Filippi, M., Asadi, N., Zare, M., Šlechta, S., and Churáčková, Z., 2009, Surficial deposits on salt diapirs (Zagros Mountains and Persian Gulf Platform, Iran) Characterization, evolution, erosion and the influence on landscape morphology: Geomorphology, v. 107, p. 195-209, doi:10.1016/j.geomorph.2008.12.006

Burr, D.M., Tanaka, K.L., and Yoshikawa, K., 2009, Pingos on Earth and Mars: Planetary and Space Science, v. 57 , p. 541-555, doi:10.1016/j.pss.2008.11.003.
Cady, S.L., and Farmer, J.D., 1996, Fossilization processes in siliceous thermal springs: Trends in preservation along thermal gradients, in Bock, G.R., and Goode, J.A., eds., Evolution of Hydrothermal Ecosystems on Earth (and Mars?) (Ciba Foundation Symposium 202): Chichester, UK, John Wiley \& Sons, Ltd., p. 150-173.

Carter, J., Poulet, F., Bibring, J.P., Mangold, N., and Murchie, S., 2013, Hydrous minerals on Mars as seen by the CRISM and OMEGA imaging spectrometers: Updated global view: Journal of Geophysical Research, v. 118, p. 831-858, doi:10.1029/2012JE004145

Cavalazzi, B., Barbieri, R., and Ori, G.G., 2007, Chemosynthetic microbialites in the Devonian carbonate mounds of Hamar Laghdad (Anti-Atlas, Morocco): Sedimentary Geology, v. 200, p. 73-88, doi:10.1016/j.sedgeo 2007.03.002.

Cavalazzi, B., Barbieri, R., Cady, S.L., George, A.D., Gennaro, S., Westall, F., Lui, A., Canteri, R., Rossi, A.P., Ori, G.G., and Taj-Eddine, K., 2012, Iron-framboids in the hydrocarbon-related Middle Devonian Hollard Mound of the Anti-Atlas mountain range in Morocco: Evidence of potential microbial biosignatures: Sedimentary Geology, v. 263-264, p. 183-193, doi:10.1016/j.sedgeo.2011.09.007.

Chan, M.A., Yonkee, W.A., Netoff, D.I., Seiler, W.M., and Ford, R.L., 2008, Polygonal cracks in bedrock on Earth and Mars: Implications for weathering: Icarus, v. 194, p. 65-71, doi:10.1016/j.icarus.2007.09.026.

Chapman, M.G., and Tanaka, K.L., 2001, Interior trough deposits on Mars: Subice volcanoes?: Journal of Geophysical Research, v. 106, p. 10,087-10,100, doi:10 1029/2000JE001303.

Chapman, M.G., and Tanaka, K.L., 2002, Related magmaice interactions: Possible origins of chasmata, chaos, and surface materials in Xanthe, Margaritifer, Meridiani Terrae, Mars: Icarus, v. 155 , p. 324-339, doi:10 1006/icar.2001.6735.

Chavdarian, G.V., and Sumner, D.Y., 2006, Cracks and fins in sulfate sand: Evidence for recent mineral-atmospheric water cycling in Meridiani Planum outcrops?: Geology, v. 34, no. 4, p. 229-232.

Clark, R.N., King, T.V.V., Klejwa, M., Swayze, G.A., and Vergo, N., 1990, High spectral resolution reflectance spectroscopy of minerals: Journal of Geophysical Research, v. 95, p. 12,653-12,680, doi:10.1029 JB095iB08p12653.

De Filippis, L., Faccenna, C., Billi, A., Anzalone, E., Brilli, M., Soligo, M., and Tuccimei, P., 2013, Plateau versus fissure ridge travertines from Quaternary geothermal springs of Italy and Turkey: Interactions and feedbacks between fluid discharge, paleoclimate, and tectonics: Earth-Science Reviews, v. 123, p. 35-52, doi:10.1016/j earscirev.2013.04.004

Dohm, J.M., Barlow, N.G., Anderson, R.C., Williams, J.P., Miyamoto, H., Ferris, J.C., Strom, R.G., Taylor, G.J., Fairén, A.G., Baker, V.R., Boynton, W.V., Keller, J.M., Kerry, K., Janes, D., Rodriguez, J.A.P., and Hare, T.M., 2007, Possible ancient giant basin and related water enrichment in the Arabia Terra province, Mars: Icarus, v. 190, p. 74-92, doi:10.1016/j.icarus.2007.03.006

Dohm, J.M., Miyamoto, H., Ori, G.G., Fairén, A.G., Davila, A.F., Komatsu, G., Mahaney, W.C., Williams, J.P., Joye, S.B., Di Achille, G., Oehler, D.Z., Marzo, G.A., Schulze-Makuch, D., Acocella, V., Glamoclija, M., Pondrelli, M., Boston, P., Hart, K.M., Anderson, R.C., Baker, V.R., Fink, W., Kelleher, B.P., Furfaro, R., Gross, C., Hare, T.M., Frazer, A.R., Ip, F., Allen, C.C.R., Kim, K.J., Maruyama, S., McGuire, P.C., Netoff, D., Parnell, J., Wendt, L., Wheelock, S.J., Steele, A., Hancock, R.G.V., Havics, R.A., Costa, P., and Krinsley, D., 2011, An inventory of potentially habitable environments on Mars: Geological and biological perspectives, in Garry, W.B., and Bleacher, J.E., eds., Analogs for Planetary Exploration: Geological Society of America Special Paper 483, p. 317-347, doi:10.1130/2011.2483(21).

Dong, H., Rech, J.A., Jiang, H., Sun, H., and Buck, B.J., 2007, Endolithic cyanobacteria in soil gypsum: Occurrences in Atacama (Chile), Mojave (United States), and Al-Jafr Basin (Jordan) Deserts: Journal of Geophysical Research, v. 112, G02030, doi:10.1029 12006JG000385.
Edgett, K.S., and Malin, M.C., 2002, Martian sedimentary rock stratigraphy: Outcrops and interbedded craters of northwest Sinus Meridiani and southwest Arabia Terra: Geophysical Research Letters, v. 29, 2179, doi: 10.1029/2002GL016515.

El-Maarry, M.R., Pommerol, A., and Thomas, N., 2013 , Analysis of polygonal cracking patterns in chloridebearing terrains on Mars: Indicators of ancient playa settings: Journal of Geophysical Research, v. 118, p. 2263-2278, doi:10.1002/2013JE004463.

El-Maarry, M.R., Watters, W., McKeown, N.K., Carter, J., Noe Dobrea, E., Bishop, J.L., Pommerol, A., and Thomas, N., 2014, Potential desiccation cracks on Mars: A synthesis from modeling, analogue-field studies, and global observations: Icarus, v. 241 , p. 248 268, doi:10.1016/j.icarus.2014.06.033.

Franchi, F., Rossi, A.P., Pondrelli, M., and Cavalazzi, B., 2014, Geometry, stratigraphy and evidences for fluid expulsion within Crommelin crater deposits, Arabia Terra, Mars: Planetary and Space Science, v. 92, p. 3448, doi:10.1016/j.pss.2013.12.013.

French, H.M., 2007, The Periglacial Environment: Chichester, UK, John Wiley \& Sons, 449 p.

Fryberger, S.G., Schenk, C.J., and Krystinik, L.F., 1988 , Stokes surfaces and the effects of near-surface groundwater-table on aeolian deposition: Sedimentology, v. 35 , no. 1 , p. $21-41$, doi:10.1111/j.1365-3091.1988 .tb00903.x.

Garvin, J., Sakimoto, S., and Frawley, J., 2003, Crater on Mars: Global geometric properties from gridded MOLA topography, in Proceedings, Sixth Internationa Conference on Mars, Pasadena, California, 20-25 July 2003: Lunar and Planetary Institute, Houston, Texas, USA, abstract 3277

Gendrin, A., Mangold, N., Bibring, J., Langevin, Y., Gondet, B., Poulet, F., Bonello, G., Quantin, C., Mustard, J., and Arvidson, R., 2005, Sulfates in Martian layered terrains: The OMEGA/Mars Express view: Science, v. 307, p. 1587-1591, doi:10.1126/science. 1109087.

Glamoclija, M., Fogel, M.L., and Steele, A., 2011, Microbial nitrogen and sulfur cycles at the playa and playa-lake deposits of White Sands National Monument, New Mexico, in Proceedings, American Geophysical Union 2011 Fall Meeting, San Francisco, California, 5-9 December: American Geophysical Union, San Francisco, California, USA, abstract B51G-0479.

Glamoclija, M., Fogel, M.L., Steele, A., and Kish, A., 2012, Microbial nitrogen and sulfur cycles at the gypsum dunes of White Sands National Monument, New Mex ico: Geomicrobiology Journal, v. 29, p. 733-751, doi: 10.1080/01490451.2011.608111.

Glotch, T.D., Bandfield, J.L., Christensen, P.R., Calvin, W.M., McLennan, S.M., Clark, B.C., Rogers, A.D. and Squyres, S.W., 2006, Mineralogy of the light-toned outcrop at Meridiani Planum as seen by the Miniature Thermal Emission Spectrometer and implications for its formation: Journal of Geophysical Research, v. 111 E12S03, doi:10.1029/2005JE002672.

Grotzinger, J., Arvidson, R., Bell, J., III, Calvin, W., Clark, B., Fike, D., Golombek, M., Greeley, R., Haldemann, A., and Herkenhoff, K., 2005, Stratigraphy and sedimentology of a dry to wet eolian depositional system, Burns formation, Meridiani Planum, Mars: Earth and Planetary Science Letters, v. 240, p. 11-72, doi:10 1016/j.eps1.2005.09.039.

Gurney, S.D., 1998, Aspects of the genesis and geomorphology of pingos: Perennial permafrost mounds: Progress in Physical Geography, v. 22, p. 307-324, doi:10.1177 /030913339802200301

Hartmann, W.K., 2005, Martian cratering 8: Isochron refinement and the chronology of Mars: Icarus, v. 174, p. 294-320.

Hartmann, W.K., and Neukum, G., 2001, Cratering chronology and the evolution of Mars: Space Science Reviews, v. 96, p. 165-194, doi:10.1023/A:1011945222010.

Hollister, E.B., Engledow, A.S., Hammett, A.J.M., Provin, T.L., Wilkinson, H.H., and Gentry, T.J., 2010, Shifts in microbial community structure along an ecological gradient of hypersaline soils and sediments: The ISME Journal, v. 4, p. 829-838, doi:10.1038/ismej.2010.3.

Hynek, B.M., Arvidson, R.E., and Phillips, R.J., 2002, Geologic setting and origin of Terra Meridiani hematite 
deposit on Mars: Journal of Geophysical Research, v. 107, 5088, doi:10.1029/2002JE001891.

Hynek, B.M., Phillips, R.J., and Arvidson, R.E., 2003 , Explosive volcanism in the Tharsis region: Global evidence in the Martian geologic record: Journal of Geophysical Research, v. 108, 5111, doi:10.1029 /2003JE002062.

Ivanov, B.A., 2001, Mars/Moon cratering rate ratio estimates: Space Science Reviews, v. 96, p. 87-104, doi: 10.1023/A: 1011941121102

Jaumann, R., Neukum, G., Behnke, T., Duxbury, T.C., Eichentopf, K., Flohrer, J., van Gasselt, S., Giese, B., Gwinner, K., Hauber, E., Hoffmann, H., Hoffmeister, A., Köhler, U., Matz, K.D., McCord, T.B., Mertens, V., Oberst, J., Pischel, R., Reiss, D., Ress, E., Roatsch, T., Saiger, P., Scholten, F., Schwarz, G., Stephan, K, and Wählisch, M., 2007, The high-resolution stereo camera (HRSC) experiment on Mars Express: Instrument aspects and experiment conduct from interplanetary cruise through the nominal mission: Planetary and Space Science, v. 55, p. 928-952, doi:10.1016/j.pss .2006.12.003.

Kerber, L., Head, J.W., Madeleine, J.-B., Forget, F., and Wilson, L., 2012, The dispersal of pyroclasts from ancient explosive volcanoes on Mars: Implications for the friable layered deposits: Icarus, v. 219 , p. 358-381, doi: 10.1016/j.icarus.2012.03.016

Kite, E.S., Halevy, I., Kahre, M.A., Wolff, M.J., and Manga, M., 2013a, Seasonal melting and the formation of sedimentary rocks on Mars, with predictions for the Gale Crater mound: Icarus, v. 223, p. 181-210, doi:10.1016 /j.icarus.2012.11.034

Kite, E.S., Lewis, K.W., Lamb, M.P., Newman, C.E., and Richardson, M.I., 2013b, Growth and form of the mound in Gale Crater, Mars: Slope wind enhanced erosion and transport: Geology, v. 41, p. 543-546, doi:10 $.1130 / \mathrm{G} 33909.1$

Knauth, L.P., Burt, D.M., and Wohletz, K.H., 2005, Impact origin of sediments at the Opportunity landing site on Mars: Nature, v. 438 , p. $1123-1128$, doi:10.1038 /nature04383.

Kneissl, T., van Gasselt, S., and Neukum, G., 2011, Mapprojection-independent crater size-frequency determination in GIS environments: New software tool for ArcGIS: Planetary and Space Science, v. 59, p. 1243 1254, doi:10.1016/j.pss.2010.03.015

Komatsu, G., Gabriele Ori, G., Ciarcelluti, P., and Litasov, Y.D., 2004, Interior layered deposits of Valles Marineris, Mars: Analogous subice volcanism related to Baikal Rifting, Southern Siberia: Planetary and Space Science, v. 52, p. 167-187, doi:10.1016/j.pss.2003.08 .003 .

Le Deit, L., Le Mouélic, S., Bourgeois, O., Combe, J.P., Mège, D., Sotin, C., Gendrin, A., Hauber, E., Mangold, N., and Bibring, J.P., 2008, Ferric oxides in East Candor Chasma, Valles Marineris (Mars) inferred from analysis of OMEGA/Mars Express data: Identification and geological interpretation: Journal of Geophysical Research, v. 113, E07001, doi:10.1029/2007JE002950.

Le Deit, L., Bourgeois, O., Mège, D., Hauber, E., Le Mouélic, S., Massé, M., Jaumann, R., and Bibring, J.P., 2010, Morphology, stratigraphy, and mineralogical composition of a layered formation covering the plateaus around Valles Marineris, Mars: Implications for its geological history: Icarus, v. 208, p. 684-703, doi: 10.1016/j.icarus.2010.03.012

Le Deit, L., Hauber, E., Fueten, F., Pondrelli, M., Rossi, A.P., and Jaumann, R., 2013, Sequence of infilling events in Gale crater, Mars: Results from morphology, stratigraphy, and mineralogy: Journal of Geophysical Research, v. 118 , p. 2439-2473, doi:10.1002/2012JE004322.

Lewis, K.W., and Aharonson, O., 2014, Occurrence and origin of rhythmic sedimentary rocks on Mars: Journal of Geophysical Research, v. 119, p. 1432-1457, doi:10 1002/2013JE004404.

Lewis, K.W., Aharonson, O., Grotzinger, J.P., Kirk, R.L., McEwen, A.S., and Suer, T.A., 2008, Quasi-periodic bedding in the sedimentary rock record of Mars: Science, v. 322 , p. $1532-1535$, doi:10.1126/science .1161870 .

Lucchetti, A, Pozzobon, R, Cremonese, G., Massironi, M Rossi, A.P., Marinangeli, L., and Martellato, E., 2014,
Filled craters in Arabia Terra: Numerical modelling results from Firsoff crater, in Proceedings, 45th Lunar and Planetary Science Conference, The Woodlands, Texas, 17-21 March 2014: Houston, Lunar and Planetary Institute, abstract 1728 .

Lucchitta, B., McEwen, A., Clow, G., Geissler, P., Singer, R., Schultz, R., and Squyres, S., 1992, The canyon system on Mars: Mars, v. 1, p. 453-492.

MacClune, K.L., Fountain, A.G., Kargel, J.S., and MacAyeal, D.R., 2003, Glaciers of the McMurdo dry valleys: Terrestrial analog for Martian polar sublimation: Journal of Geophysical Research, v. 108, 5031, doi:10 .1029/2002JE001878

Madden, M.E.E., Bodnar, R., and Rimstidt, J., 2004, Jarosite as an indicator of water-limited chemical weathering on Mars: Nature, v. 431, p. 821-823, doi:10.1038 Inature02971.

Malin, M.C., and Edgett, K.S., 2000, Sedimentary rocks of early Mars: Science, v. 290, p. 1927-1937, doi:10.1126 /science.290.5498.1927.

Malin, M.C., Bell, J.F., III, Cantor, B.A., Caplinger, M.A., Calvin, W.M., Clancy, R.T., Edgett, K.S., Edwards, L., Haberle, R.M., and James, P.B., 2007, Context Camera investigation on board the Mars Reconnaissance Orbiter: Journal of Geophysical Research, v. 112, E05S04, doi:10.1029/2006JE002808.

Mangold, N., Gendrin, A., Gondet, B., LeMouelic, S., Quantin, C., Ansan, V., Bibring, J.-P., Langevin, Y. Masson, P., and Neukum, G., 2008, Spectral and geological study of the sulfate-rich region of West Candor Chasma, Mars: Icarus, v. 194, p. 519-543, doi:10.1016 /j.icarus. 2007.10.021.

McEwen, A.S., Eliason, E.M., Bergstrom, J.W., Bridges, N.T., Hansen, C.J., Delamere, W.A., Grant, J.A., Gulick, V.C., Herkenhoff, K.E., Keszthelyi, L., Kirk, R.L., Mellon, M.T., Squyres, S.W., Thomas, N., and Weitz, C.M., 2007, Mars Reconnaissance Orbiter's High Resolution Imaging Science Experiment (HiRISE): Journal of Geophysical Research, v. 112, E05S02, doi 10.1029/2005JE002605

McLennan, S.M., Bell, J.F., III, Calvin, W.M., Christensen, PR, Clark, B.C., de Souza, P.A., Farmer, J., Farrand, W.H., Fike, D.A., Gellert, R., Ghosh, A., Glotch, T.D. Grotzinger, J.P., Hahn, B., Herkenhoff, K.E., Hurowitz, J.A., Johnson, J.R., Johnson, S.S., Jolliff, B., Klingelhöfer, G., Knoll, A.H., Learner, Z., Malin, M.C., McSween, H.Y., Jr., Pocock, J., Ruff, S.W., Soderblom, L.A., Squyres, S.W., Tosca, N.J., Watters, W.A., Wyatt, M.B., and Yen, A., 2005, Provenance and diagenesis of the evaporite-bearing Burns formation, Meridian Planum, Mars: Earth and Planetary Science Letters, v. 240, p. 95-121, doi:10.1016/j.epsl.2005.09.041.

Michael, G.G., 2013, Planetary surface dating from crater size-frequency distribution measurements: Multiple resurfacing episodes and differential isochron fitting: Icarus, v. 226, p. 885-890, doi:10.1016/j.icarus.2013 .07 .004 .

Michael, G.G., and Neukum, G., 2010, Planetary surface dating from crater size-frequency distribution measurements: Partial resurfacing events and statistical age uncertainty: Earth and Planetary Science Letters, v. 294, p. 223-229, doi:10.1016/j.epsl.2009.12.041.

Michael, G.G., Platz, T., Kneissl, T., and Schmedemann, N., 2012, Planetary surface dating from crater sizefrequency distribution measurements: Spatial randomness and clustering: Icarus, v. 218, p. 169-177, doi:10 $.1016 /$ j.icarus.2011.11.033.

Michalski, J.R., and Bleacher, J.E., 2013, Supervolcanoes within an ancient volcanic province in Arabia Terra, Mars: Nature, v. 502, p. 47-52, doi: 10.1038 /nature 12482.

Michalski, J., and Niles, P.B., 2012, Atmospheric origin of Martian interior layered deposits: Links to climate change and the global sulfur cycle: Geology, v. 40, p. 419-422, doi:10.1130/G32971.1.

Michalski, J.R., Cuadros, J., Niles, P.B., Parnell, J., Deanne Rogers, A., and Wright, S.P., 2013a, Groundwater activity on Mars and implications for a deep biosphere: Nature Geoscience, v. 6, p. 133-138, doi:10.1038 /ngeo1706.

Michalski, J.R., Niles, P.B., Cuadros, J., and Baldridge, A.M., 2013b, Multiple working hypotheses for the formation of compositional stratigraphy on Mars: Insights from the Mawrth Vallis region: Icarus, v. 226 , p. 816-840, doi:10.1016/j.icarus.2013.05.024.

Moratto, Z.M., Broxton, M.J., Beyer, R.A., Lundy, M., and Husmann, K., 2010, Ames Stereo Pipeline, NASA's open source automated stereogrammetry software, in Proceedings, 41st Lunar and Planetary Science Conference, The Woodlands, Texas, 1-5 March 2010: Houston, Lunar and Planetary Institute, abstract 2364.

Morgan, F., Seelos, F.P., Murchie, S.L., and the CRISM Team, 2014, CRISM Analysis Toolkit (CAT), in Gaddis, R.G., Hare, T., and Beyer, R., eds., Summary and Abstracts of the Planetary Data Workshop, June 2012: Open-File Report 2014-1056, U.S. Geological Survey, Reston, VA, USA, p. 125-126.

Müller, F., 1959, Beobachtungen über Pingos: Detailuntersuchungen in Ostgrönland und in der kanadischen Arktis: Meddelelser om Grønland, v. 153, 127 p.

Murana, A., and Kneissl, T., 2014, Stratigraphic analysis of the depositional sequence in Danielson Crater, Mars, in Rocha, R., Pais, J., Kullberg, J.C., and Finney, S., eds. STRATI 2013: First International Congress on Stratigraphy at the Cutting Edge of Stratigraphy: Springer, p. 337-341.

Murchie, S., Arvidson, R., Bedini, P., Beisser, K., Bibring, J.P., Bishop, J., Boldt, J., Cavender, P., Choo, T., Clancy, R.T., Darlington, E.H., Des Marais, D., Espiritu, R. Fort, D., Green, R., Guinness, E., Hayes, J., Hash, C. Heffernan, K., Hemmler, J., Heyler, G., Humm, D., Hutcheson, J., Izenberg, N., Lee, R., Lees, J., Lohr, D., Malaret, E., Martin, T., McGovern, J.A., McGuire, P. Morris, R., Mustard, J., Pelkey, S., Rhodes, E., Robinson, M., Roush, T., Schaefer, E., Seagrave, G., Seelos, F., Silverglate, P., Slavney, S., Smith, M., Shyong, W.J., Strohbehn, K., Taylor, H., Thompson, P., Tossman, B. Wirzburger, M., and Wolff, M., 2007, Compact Reconnaissance Imaging Spectrometer for Mars (CRISM) on Mars Reconnaissance Orbiter (MRO): Journal of Geophysical Research: Planets, v. 112, no. E5, E05S03, doi: 10.1029/2006JE002682.

Murchie, S., Roach, L., Seelos, F., Milliken, R., Mustard, J., Arvidson, R., Wiseman, S., Lichtenberg, K., AndrewsHanna, J., Bishop, J., Bibring, J.-P., Parente, M., and Morris, R., 2009, Evidence for the origin of layered deposits in Candor Chasma, Mars, from mineral composition and hydrologic modeling: Journal of Geophysica Research, v. 114, E00D05, doi:10.1029/2009JE003343.

Mustard, J.F., Murchie, S.L., Pelkey, S.M., Ehlmann, B.L. Milliken, R.E., Grant, J.A., Bibring, J.P., Poulet, F. Bishop, J., Dobrea, E.N., Roach, L., Seelos, F., Arvidson, R.E., Wiseman, S., Green, R., Hash, C., Humm, D., Malaret, E., McGovern, J.A., Seelos, K., Clancy, T., Clark, R., Marais, D.D., Izenberg, N., Knudson, A., Langevin, Y., Martin, T., McGuire, P., Morris, R., Robinson, M., Roush, T., Smith, M., Swayze, G., Taylor, H., Titus, T., and Wolff, M., 2008, Hydrated silicate minerals on Mars observed by the Mars Reconnaissance Orbiter CRISM instrument: Nature, v. 454 p. 305-309, doi:10.1038/nature07097.

Neukum, G., Jaumann, R., and the HRSC Co-Investigator and Experiment Team, 2004, HRSC: The High Resolution Stereo Camera of Mars Express, in Wilson, A., ed. Mars Express: The Scientific Payload: European Space Agency Special Publication SP-1240, p. 17-35.

Newsom, H.E., Barber, C.A., Hare, T.M., Schelble, R.T. Sutherland, V.A., and Feldman, W.C., 2003, Paleolakes and impact basins in southern Arabia Terra, including Meridiani Planum: Implications for the formation of hematite deposits on Mars: Journal of Geophysical Research, v. 108, 8075, doi:10.1029/2002JE001993.

Newsom, H.E., Lanza, N.L., Ollila, A.M., Wiseman, S.M., Roush, T.L., Marzo, G.A., Tornabene, L.L., Okubo, C.H., Osterloo, M.M., Hamilton, V.E., and Crumpler, L.S., 2010, Inverted channel deposits on the floor of Miyamoto crater, Mars: Icarus, v. 205, p. 64-72, doi: 10.1016/j.icarus.2009.03.030

Oehler, D.Z., and Allen, C.C., 2010, Evidence for pervasive mud volcanism in Acidalia Planitia, Mars: Icarus, v. 208, p. 636-657, doi:10.1016/j.icarus.2010.03.031.

Okubo, C., Schultz, R., Chan, M., and Komatsu, G., 2009, Deformation band clusters on Mars and implications for subsurface fluid flow: Geological Society of 
America Bulletin, v. 121, p. 474-482, doi:10.1130 /B26421.1.

Ori, G.G., and Baliva, A., 1999, Large bulges at the center of impact craters on Mars, in Proceedings, 30th Lunar and Planetary Science Conference, Houston, 15-19 March 1999: Houston, Lunar and Planetary Institute, abstract 1758 .

Panieri, G., Lugli, S., Manzi, V., Roveri, M., Schreiber, B.C., and Palinska, K.A., 2010, Ribosomal RNA gene fragments from fossilized cyanobacteria identified in primary gypsum from the late Miocene, Italy: Geobiology, v. 8, p. 101-111, doi:10.1111/j.1472-4669.2009 $.00230 . x$.

Parnell, J., Taylor, C.W., Thackrey, S., Osinski, G.R., and Lee, P., 2010, Permeability data for impact breccias imply focussed hydrothermal fluid flow: Journal of Geochemical Exploration, v. 106, p. 171-175, doi:10 $.1016 /$ j.gexplo.2009.12.002.

Pelkey, S.M., Mustard, J.F., Murchie, S., Clancy, R.T. Wolff, M., Smith, M., Milliken, R., Bibring, J.-P., Gendrin, A., Poulet, F., Langevin, Y., and Gondet, B., 2007 CRISM multispectral summary products: Parameterizing mineral diversity on Mars from reflectance: Journal of Geophysical Research, v. 112, E08S14, doi:10.1029 /2006JE002831.

Pentecost, A., 2005, Travertine: Berlin, Springer, 445 p

Pondrelli, M., Rossi, A.P., Ori, G.G., van Gasselt, S., Praeg, D., and Ceramicola, S., 2011a, Mud volcanoes in the geologic record of Mars: The case of Firsoff crater: Earth and Planetary Science Letters, v. 304, p. $511-$ 519, doi:10.1016/j.eps1.2011.02.027.

Pondrelli, M., Rossi, A.P., Platz, T., Ivanov, A., Marinangeli, L., and Baliva, A., 2011b, Geological, geomorphologi$\mathrm{cal}$, facies and allostratigraphic maps of the Eberswalde fan delta: Planetary and Space Science, v. 59, p. 1166 1178, doi:10.1016/j.pss.2010.10.009.

Poulet, F., Arvidson, R.E., Gomez, C., Morris, R.V., Bibring, J.P., Langevin, Y., Gondet, B., and Griffes, J., 2008, Mineralogy of Terra Meridiani and western Arabia Terra from OMEGA/MEx and implications for their formation: Icarus, v. 195, no. 1, p. 106-130.

Pozzobon, R., Mazzarini, F., Massironi, M., Pondrelli, M., Rossi, A.P., and Marinangeli, L., 2013, Fractal analysis and possible fluid source depth in crater mounds, Arabia Terra (Mars), in Proceedings, 44th Lunar an Planetary Science Conference, The Woodlands, Texas, 18-22 March 2013: Houston, Lunar and Planetary Institute, abstract 2113 .

Rossi, A.P., Neukum, G., Pondrelli, M., van Gasselt, S., Zegers, T., Hauber, E., Chicarro, A., and Foing, B. 2008, Large-scale spring deposits on Mars?: Journal of Geophysical Research, v. 113, E08016, doi:10.1029 /2007JE003062.
Rossi, A.P., Pondrelli, M., Hauber, E., Baliva, A., Michael, G., Ori, G.G., Pompilio, L., Parente, M., Ivanov, A., and Neukum, G., 2009, Stratigraphic architecture and structural control on sediment emplacement in Becquerel crater (Mars), in Proceedings, 40th Lunar and Planetary Science Conference, The Woodlands, Texas, 23-27 March 2009: Houston, Lunar and Planetary Institute, abstract 1588 .

Schieber, J., 2007, Reinterpretation of the Martian Eberswalde Delta in the light of new HiRISE images, in Proceedings, 38th Lunar and Planetary Science Conference, League City, Texas, 12-16 March 2007: Houston, Lunar and Planetary Institute, abstract 1982

Schultz, P.H., Schultz, R.A., and Rogers, J., 1982, The structure and evolution of ancient impact basins on Mars: Journal of Geophysical Research, v. 87, no. B12, p. 9803-9820

Scott, D.H., and Tanaka, K.L., 1982, Ignimbrites of Amazonis Planitia region of Mars: Journal of Geophysical Research, v. 87, p. 1179-1190, doi:10.1029 /JB087iB02p01179.

Scott, D.H., and Tanaka, K.L, 1986, Geologic map of the western equatorial region of Mars: U.S. Geological Survey Miscellaneous Investigations Series Map I-1802-A, scale 1:15,000,000.

Smith, D.E., Zuber, M.T., Solomon, S.C., Phillips, R.J., Head, J.W., Garvin, J.B., Banerdt, W.B., Muhleman, D.O., Pettengill, G.H., Neumann, G.A., Lemoine, F.G., Abshire, J.B., Aharonson, O., Brown, C.D., Hauck, S.A., Ivanov, A.B., McGovern, P.J., Zwally, H.J., and Duxbury, T.C., 1999, The global topography of Mars and implications for surface evolution: Science, v. 284 p. 1495-1503, doi:10.1126/science.284.5419.1495

Stokes, W.L., 1968, Multiple parallel-truncation bedding planes: A feature of wind-deposited sandstone formations: Journal of Sedimentary Research, v. 38, p. $510-515$

Sullivan, R., Anderson, R., Biesiadecki, J., Bond, T., and Stewart, H., 2011, Cohesions, friction angles, and other physical properties of Martian regolith from Mars Exploration Rover wheel trenches and wheel scuffs: Journal of Geophysical Research, v. 116, E02006, doi:10 1029/2010JE003625.

Szynkiewicz, A., Modelska, M., Buczyński, S., Borrok, D.M., and Merrison, J.P., 2013, The polar sulfur cycle in the Werenskioldbreen, Spitsbergen: Possible implications for understanding the deposition of sulfate minerals in the North Polar Region of Mars: Geochimica et Cosmochimica Acta, v. 106, p. 326-343, doi:10.1016/j gca.2012.12.041

Tanaka, K.L., 2000, Dust and ice deposition in the Martian geologic record: Icarus, v. 144, p. 254-266, doi:10 .1006/icar.1999.6297.
Tanaka, K.L., Skinner, J.A., Jr., Dohm, J.M., Irwin, R.P., III, Kolb, E.J., Fortezzo, C.M., Platz, T., Michael, G.G., and Hare, T.M., 2014, Geologic map of Mars: U.S. Geological Survey Scientific Investigations Map 3292, scale 1:20,000,000, 43 p., doi:10.3133/sim3292.

Thomas, P., Squyres, S., Herkenhoff, K., Howard, A., and Murray, B., 1992, Polar deposits of Mars, in Kieffer, H.H., Jakosky, B.M., Snyder, C.W., and Matthews, M.S., eds., Mars: Tucson, Arizona, University of Arizona Press, p. 767-795

Tosca, N.J., McLennan, S.M., Clark, B.C., Grotzinger, J.P., Hurowitz, J.A., Knoll, A.H., Schröder, C., and Squyres, S.W., 2005, Geochemical modeling of evaporation processes on Mars: Insight from the sedimentary record at Meridiani Planum: Earth and Planetary Science Letters, v. 240, p. 122-148, doi:10.1016/j.epsl.2005.09.042.

Tosca, N.J., Knoll, A.H., and McLennan, S.M., 2008, Water activity and the challenge for life on early Mars: Science, v. 320, p. 1204-1207, doi:10.1126/science .1155432 .

Ventosa, A., Mellado, E., Sanchez-Porro, C., and Marquez, M.C., 2008, Halophilic and halotolerant microorganisms from soils, in Dion, P., and Nautiyal, C. eds., Microbiology of Extreme Soils: Berlin, Heidelberg, Springer, p. 87-115.

Walter, M.R., and Des Marais, D.J., 1993, Preservation of biological information in thermal spring deposits: Developing a strategy for the search for fossil life on Mars: Icarus, v. 101, p. 129-143, doi:10.1006/icar.1993.1011.

Williams, J.-P., Paige, D.A., and Manning, C.E., 2003, Layering in the wall rock of Valles Marineris: Intrusive and extrusive magmatism: Geophysical Research Letters, v. 30, 1623, doi:10.1029/2003GL017662.

Wiseman, S.M., Arvidson, R.E., Morris, R.V., Poulet, F., Andrews-Hanna, J.C., Bishop, J.L., Murchie, S.L., Seelos, F.P., Des Marais, D., and Griffes, J.L., 2010, Spectral and stratigraphic mapping of hydrated sulfate and phyllosilicate-bearing deposits in northern Sinus Meridiani, Mars: Journal of Geophysical Research, v. 115, E00D18, doi:10.1029/2009JE003354.

Zabrusky, K., Andrews-Hanna, J.C., and Wiseman, S.M. 2012, Reconstructing the distribution and depositional history of the sedimentary deposits of Arabia Terra, Mars: Icarus, v. 220, p. 311-330, doi:10.1016/j.icarus 2012.05.007. 